Argonne Rational Laboratom

AN EMPIRICAL MODIFICATION OF NUCLEATION THEORY AND ITS APPLICATION TO BOILING HEAT TRANSFER by Yan Po Chang 


\section{DISCLAIMER}

This report was prepared as an account of work sponsored by an agency of the United States Government. Neither the United States Government nor any agency Thereof, nor any of their employees, makes any warranty, express or implied, or assumes any legal liability or responsibility for the accuracy, completeness, or usefulness of any information, apparatus, product, or process disclosed, or represents that its use would not infringe privately owned rights. Reference herein to any specific commercial product, process, or service by trade name, trademark, manufacturer, or otherwise does not necessarily constitute or imply its endorsement, recommendation, or favoring by the United States Government or any agency thereof. The views and opinions of authors expressed herein do not necessarily state or reflect those of the United States Government or any agency thereof. 


\section{DISCLAIMER}

Portions of this document may be illegible in electronic image products. Images are produced from the best available original document. 
This report was prepared as an account of Government sponsored work. Neither the United States, nor the Commission, nor any person acting on behalf of the Commission:

A. Makes any warranty or representation, expressed or implied, with respect to the accuracy, completeness, or usefulness of the information contained in this report, or that the use of any information, apparatus, method, or process disclosed in this report may not infringe privately owned rights; or

B. Assumes any liabilities with respect to the use of, or for damages resulting from the use of any information, apparatus, method, or process disclosed in this report.

As used in the above, "person acting on behalf of the Commission" includes any employee or contractor of the Commission, or employee of such contractor, to the extent that such employee or contractor of the Commission, or employee of such contractor prepares, dis seminates, or provides access to, any information pursuant to his employment or contract with the Commission, or his employment with such contractor.

Price 75 cents. Available from the Office of Technical Services, Department of Commerce, Washington 25, D.C. 
ANL $-63 \overline{0} \overline{4}$

Engineering and Equipment

(TID-4500, 16th Ed.)

AEC Research and

Development Report

\section{ARGONNE NATIONAL LABORATORY \\ 9700 South Cass Avenue \\ Argonne, Illinois}

AN EMPIRICAL MODIFICATION OF NUCLEATION THEORY AND ITS APPLICATION TO BOILING HEAT TRANSFER

by

Yan Po Chang*

Argonne National Laboratory Subcontract 31-109-38-1158

February 1961

*Professor in the Department of Engineering Science,

University of Notre Dame, Notre Dame, Indiana

Operated by The University of Chicago

under

Contract W-3l-109-eng-38 


\section{TABLE OF CONTENTS}

No.

Title

Page

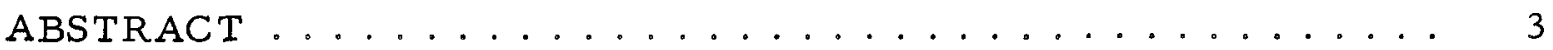

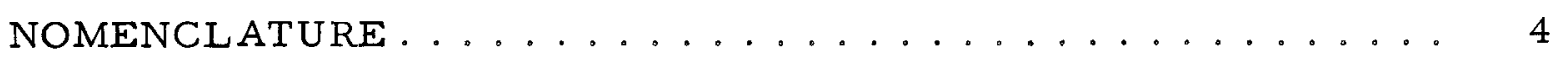

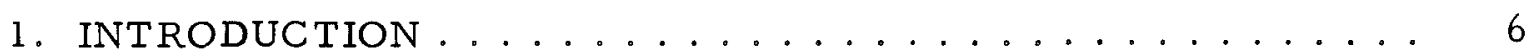

2. REVIEW OF PREVIOUS SEMITHEORETICAL

INVESTIGATIONS ......................... 7

3. MECHANISM OF NUCLE ATE BOILING ............. 9

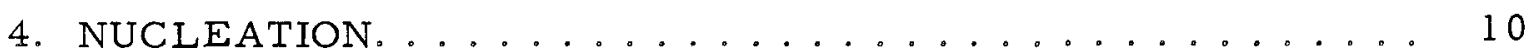

5. FUNDAMENT AL EQUATIONS AND PARAMETERS ........ II

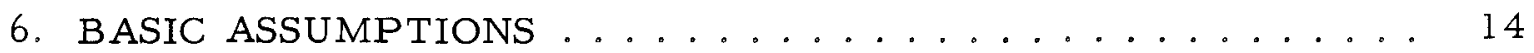

7. GENERAL EQUATION FOR HEAT TRANSFER DURING

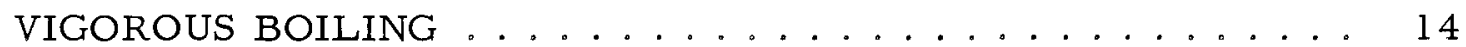

8. VIGOROUS BOILING OF ORGANIC LIQUIDS. .......... 16

9. VIGOROUS BOILING OF WATER AND OF MERCURY . . . . . 22

10. HEAT TRANSFER DURING FEEBLE BOILING ........ 25

11. PHYSICAL INTERPRET ATION OF EQ. (21) . . . . . . . . 27

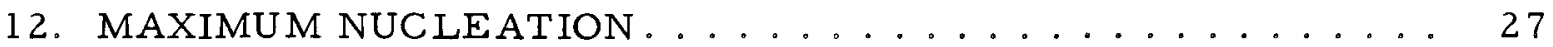

13. CONCLUSIONS AND REMARKS ............... 28

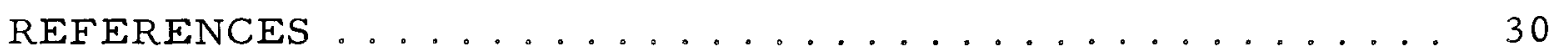

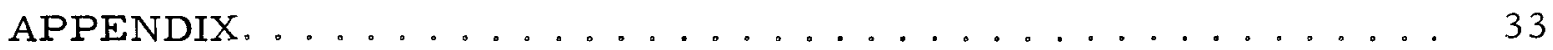




\title{
AN EMPIRIC AL MODIFICATION OF NUCLEATION THEORY AND ITS APPLICATION TO BOILING HEAT TRANSFER
}

\author{
by
}

\section{Yan Po Chang}

\begin{abstract}
From the equations of momentum and of energy and by the aid of established experimental phenomena, the problem of heat transfer in nucleate boiling is reduced to one consisting of three parameters: the first represents the Stanton number, the second bubble growth, and the third nucleation. With an empirical modification of the nucleation theory as developed by Volmer and Eyring from the MaxwellBoltzman distribution law, an equation is obtained for the heat transfer in vigorous boiling:

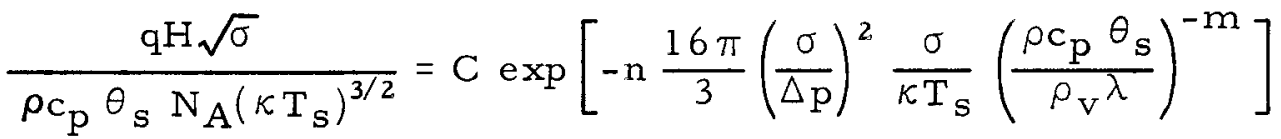

where $m=1$ and 2 for organic and inorganic liquids (including liquid metals), respectively. The symbols $\mathrm{C}$ and $\mathrm{n}$ represent dimensionless numbers whose values depend on the liquid and surface condition of the heater. Application of this equation is restricted to the following cases of boiling:

1. saturated pool boiling from either s mooth or rough surfaces;

2. saturated and subcooled forced convection boiling from rough surfaces; and

3. early stage of saturated and subcooled forced convection boiling from smooth surfaces.

The validity of this equation for vigorous boiling has been tested for more than a dozen of different liquids under different pressures and different surface conditions. By introducing an eddy thermal diffusivity, a general equation has been obtained, valid for the whole range of nucleate boiling.
\end{abstract}




\section{NOMENCLATURE}

a

Diagonal distance of bubble sites on $x z-p l a n e, f t$

C Constant coefficient depending on liquid-surface combination

$c_{p} \quad$ Specific heat of liquid at constant pressure, Btu $/\left(1 \mathrm{~b}_{\mathrm{m}}\right)\left({ }^{\circ} \mathrm{F}\right)$

D Diameter of bubble at departure from heating surface, ft, or diameter of tube, $\mathrm{ft}$

$\vec{F} \quad$ Extraneous force, $1 b$

g Gravitational acceleration, $\mathrm{ft} / \mathrm{h} \mathrm{r}^{2}$

$\mathrm{H} \quad$ Planck's constant

h Heat transfer coefficient, Btu $/\left(\mathrm{ft}^{2}\right)(\mathrm{hr})$

$\mathrm{j}$ Unit vector in $\mathrm{y}$-direction, i.e., normal to the heating surface

$k \quad$ Thermal conductivity, Btu $/\left(\mathrm{ft}^{2}\right)(\mathrm{hr})\left({ }^{\circ} \mathrm{F} / \mathrm{ft}\right)$

L Characteristic length, $\mathrm{ft}$

$\mathrm{N} \quad$ Rate of nucleation

NA Avogadro's number

$\mathrm{N}_{0} \quad$ Frequency factor

n Constant coefficient depending on surface conditions

$\Delta \mathrm{p} \quad$ Pressure difference corresponding to superheat, $\mathrm{lb} / \mathrm{ft}^{2}$

q Heat transfer rate per unit area, Btu/ $\left(\mathrm{ft}^{2}\right)(\mathrm{hr})$

$\vec{R} \quad$ Distance vector from the origin of the coordinate system to any point of the liquid, $f t$

$\vec{r} \quad$ Radius vector of the bubble, $\mathrm{ft}$

$\dot{\vec{r}} \quad$ Velocity vector of bubble growth, $\mathrm{ft} / \mathrm{hr}$

r* Critical radius of vapor bubble

$\mathrm{T} \quad$ Temperature, ${ }^{\circ} \mathrm{F}$ or ${ }^{\circ} \mathrm{R}$

t Time, hr

$\tau_{1} \quad$ Duration of bubble formation on the heating surface, $h r$

$T_{2}$ Period of bubble generation from each site, hr

$\mathrm{U} \quad$ Average velocity of forced convection, $\mathrm{ft} / \mathrm{hr}$

$\vec{V} \quad$ Instantaneous velocity of liquid

$\mathrm{X} \quad 16 / 3\left[\pi(\sigma / \Delta \mathrm{p})^{2}\right] \sigma / \kappa \mathrm{T}_{\mathrm{S}}$ 
$\mathrm{Y}$

$\alpha$

$\theta_{0}$

$\theta p$

$\theta_{\mathrm{S}}$

$\phi, \psi$

$\triangle \Phi$

$\triangle \Phi_{\max }$

$\rho c_{p} \theta_{s} / \rho_{v} \lambda$

Molecular thermal diffusivity, $\mathrm{ft}^{2} / \mathrm{hr}$

Expansion coefficient of the liquid

Boltzmann's constant

Density, $1 b_{m} / \mathrm{ft}^{3}$

Surface tension, $1 \mathrm{~b} / \mathrm{ft}$

Dynamic viscosity, $1 \mathrm{~b} /(\mathrm{ft})(\mathrm{hr})$

Kinematic viscosity, $\mathrm{ft}^{2} / \mathrm{hr}$

Eddy thermal diffusivity, $\mathrm{ft}^{2} / \mathrm{hr}$

Latent heat of vaporization of saturated liquid, Btu/ $/ b_{m}$

$\mathrm{Nu}, \mathrm{Pr}$, Nusselt, Prandtl, Reynolds, Grashof, and Peclet numbers, $\mathrm{Re}, \mathrm{Gr}$, respectively.

$\mathrm{Pe}$

Subscripts

$\begin{array}{llcl}\text { v vapor } & \text { o } & \text { bulk liquid } \\ \mathrm{s} & \text { saturated } & \text { w } & \text { wall }\end{array}$

Physical properties without subscript indicate those of liquid 


\section{INTRODUCTION}

Recent technological advances have focused ever increasing attention on the boiling phenomenon as a means of increasing the magnitude of the heat transfer per unit area. A great deal of experimental work has been done and a number of correlations for the heat transfer rate have been proposed in the light of the experimental results. Most of this work, however, has been with boiling of liquids under a pressure of one atmosphere and the circulation is usually natural.

The results for heat transfer rate from an electrically heated wire submerged in a pool of saturated liquid indicate the existence of four regimes, (1) as shown schematically in Fig. 1. At very low superheat the small number of bubbles has only a minor influence on heat transfer, and the heat transfer can be determined by the natural convection set up by the superheat.

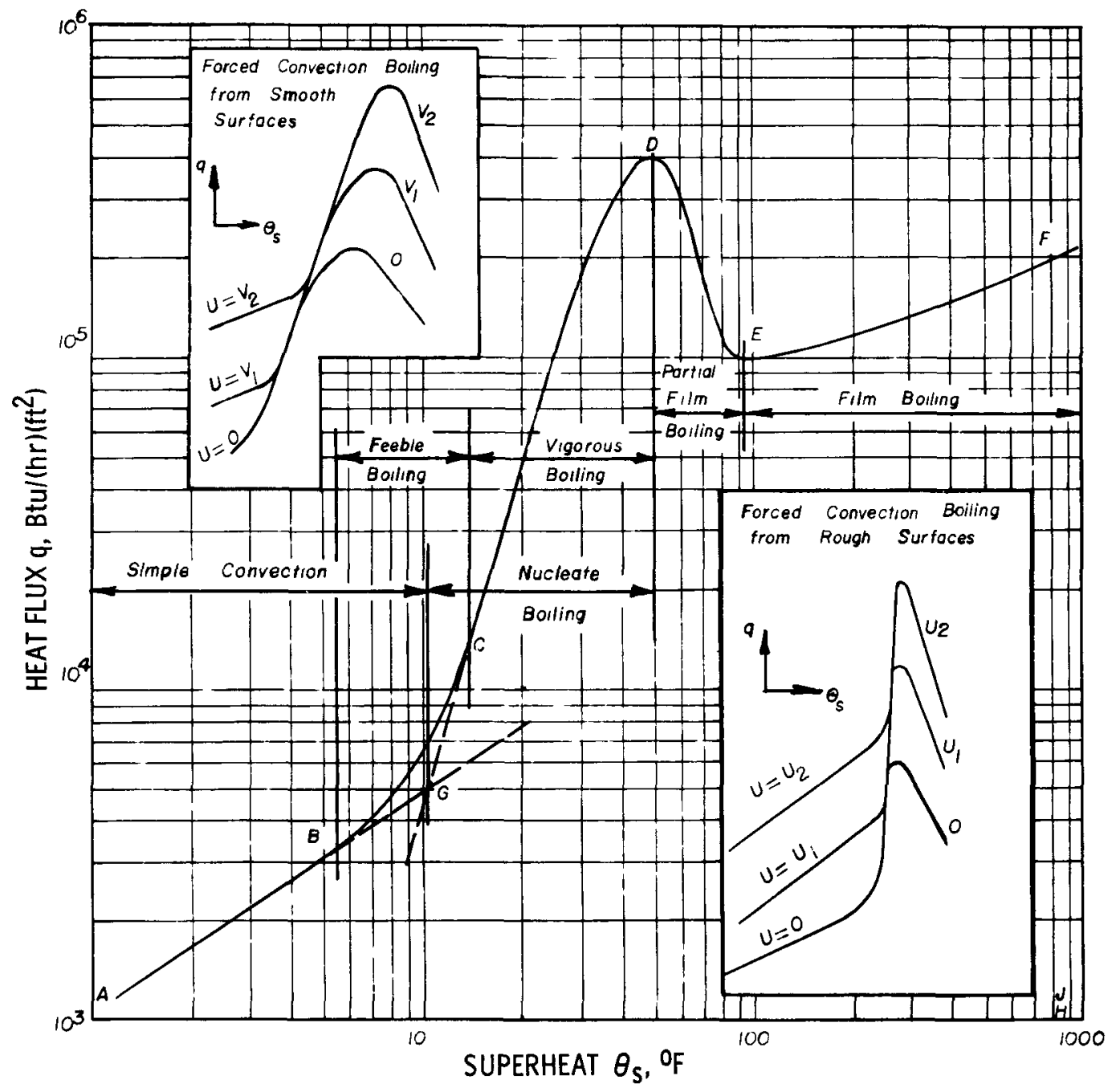

Fig. 1. Typical Boiling Curve 
Evaporation in this range, from A to G in Fig. 1, is generally called natural convection boiling. With further increase of superheat, bubbles are formed from more nuclei on the heating surface, and the contribution to heat transfer due to bubble action becomes gradually more important than that due to simple convection. The range from $G$ to $D$ is usually called nucleate boiling. In this range the bubble population increases rapidly with the increase of superheat. When the bubble population becomes high, the bubbles, before detaching from or collapsing at the heater, will be flattened and broken up into smaller bubbles of various sizes. A part of the smaller bubbles will be entrained by the turbulent liquid adjacent to the heater, forming a phenomenon more or less similar to the occurrence of "white water" in rapids or on spillways. Then the heating surface is splashed by the "white liquid" instead of by liquid alone, and the heat transfer rate starts to decrease. Thus, there is a critical value of superheat at which the heat transfer rate passes through a maximum. Previous investigators, however, considered that at this condition the bubbles tend to merge, spreading out over the heating surface and forming a partial vapor film. Therefore, the range DE has been called partial nucleate or partial film boiling, although there is no bubble coalescence at all. When the vapor blankets the entire surface, the process is called completefilm boiling, which is indicated by EF. The transition from simple convection to nucleate boiling, in fact, takes place gradually, as is shown by the solid line $\mathrm{BC}$ in Fig. 1. The ranges $\mathrm{BC}$ and $\mathrm{CD}$ are called feeble and vigorous boiling, respectively, in this paper.

Although Fig. 1 shows the boiling curve of a heated wire, its basic character holds for any heater irrespective of its size, shape, or orientation. When forcing-flow of the liquid is present and the bulk of liquid is maintained at a temperature below the saturation point, the boiling curve also exhibits a similar character. From Fig. 1 it is seen that there are, in general, two critical conditions in boiling heat transfer, one corresponding to the maximum heat flux in nucleate boiling, and the other to the inception of complete film boiling. It is convenient to refer to the former as the first critical condition and to the latter as the second.

An attempt has been made by the author to predict the complete curve $A B C D E F$ for boiling of saturated or subcooled liquids with or without forced convection, and the results will be reported in three consecutive papers. This paper represents the first and deals only with heat transfer in the ranges from $A$ to $D$.

\section{REVIEW OF PREVIOUS SEMITHEORETICAL INVESTIGATIONS}

A great number of formulae for boiling heat transfer have been empirically correlated in the past few years. Semitheoretical correlations are mostly based on the assumption that the heat transfer coefficient should be represented in a form similar to the Nusselt equation for forced convection. Rohsenow $(2)$ introduced an empirically obtained relation between 
the bubble Nusselt and bubble Reynolds numbers. The equation he found most convenient for the correlation of experimental data is

$$
\frac{c_{p} \theta_{s}}{\lambda \operatorname{Pr}^{1.7}}=C_{s f}\left[\frac{q}{\lambda \mu} \sqrt{\frac{\sigma}{g\left(\rho-\rho_{v}\right)}}\right]^{0.33},
$$

where $\mathrm{C}_{\mathrm{Sf}}$ is a constant whose value varies from 0.0027 to 0.13 , depending on the liquid-surface combinations. This equation applies only to clean surfaces. For other surface conditions, both $\mathrm{C}_{\mathbf{s f}}$ and the exponent of $\mathrm{Pr}$ are subject to change.

Forster and Grief ${ }^{(3)}$ proposed a modified relation between bubble Nusselt and Reynolds numbers. Based upon the growth rate of bubbles near the final state in a superheated liquid, they arrived at Eq. (2):

$$
q=\operatorname{const} \frac{k}{\sigma} \theta_{s} \Delta p\left(\frac{A^{2}}{\nu}\right)^{0.2} \operatorname{Pr}^{\frac{1}{3}}
$$

where

$$
\mathrm{A}=\left(\pi \mathrm{kc}_{\mathrm{p}} \rho\right)^{\frac{1}{2}} \Delta \mathrm{p} /\left(\rho_{\mathrm{v}} \lambda\right)^{2}
$$

The validity of Eq. (2) has been tested for a number of liquids at a pressure of one atmosphere and for water at one and 50 atmospheres.

For further expansion of the bubble-growth theory to determine the heat transfer rates as suggested by Forster and his associates, Levy (4) has most recently obtained Eq. (3) as a generalized correlation of boiling heat transfer:

$$
q=\frac{k c_{p} \rho^{2}}{\sigma T_{s}\left(\rho-\rho_{v}\right)} \frac{\theta_{s}^{3}}{B_{L}},
$$

where $B_{L}$ is a variable number, determined empirically, depending on the quantity $\rho_{\mathrm{v}} \lambda$, which is to be expressed in the Btu/ft ${ }^{3}$. Eq. (3) has been tested by Levy for a large range of fluids, pressures, and surface-fluid combinations.

Starting from the equations of momentum and energy, Chang and Snyder (5) obtained Eq. (4) for the heat transfer in vigorous nucleate boiling:

$$
\mathrm{q}=\operatorname{const} \frac{\mathrm{k} \Delta \mathrm{p}^{1.4} \theta_{\mathrm{s}}}{\sigma\left(\rho_{\mathrm{v}} \lambda\right)^{0.8}}\left[{ }_{\mathrm{p}} \mathrm{T}_{\mathrm{s}}\left(\rho-\rho_{\mathrm{v}}\right)\right]^{0.4} .
$$

Equation (4) has been tested for water and a number of organic liquids boiling from clean smooth surfaces. 
It is interesting to note that viscosity plays only a minor role in Eq. (2) and disappears completely from Eqs. (3) and (4). This marks the great difference between the correlation of Rohsenow and those of Forster and Grief, Levy, and Chang and Snyder. The calculated results from the above formulae, however, often deviate from test data by more than $\pm 30 \%$ and cannot apply to systems in which the heating surface is very rough.

\section{MECHANISM OF NUCLEATE BOILING}

Various mechanisms of heat transfer in nucleate boiling have been proposed by many investigators and have been extensively discussed by Forster and Grief.(3)

Jakob, (6) Gunther and Kreith, (7) Rohsenow and Clark, (8) and Ellion, (9) with the aid of photographic investigations, all concluded that agitation, or microconvection by vapor bubbles, is chiefly responsible for the high heat transfer rates, and that the latent heat transport is negligible. Snyder and Edward(10) proposed a mechanism of mass transfer. From the results of numerical calculations they arrived at the conclusion that the mass transfer through the vapor bubbles is sufficient to transfer the observed value of heat flux in subcooled boiling.

Forster and Grief(3) considered that, in addition to the latent heat transport, the bubbles also transfer heat during their growth by pushing a quantity of hot liquid from the heating surface into the cold region. Based upon experimental data, their numerical calculations showed that the exchange of liquid and vapor for each bubble volume can account for all the heat transferred in subcooled nucleate boiling.

Up to the present time, the microconvection model has been widely accepted, but, at least from the author's point of view, the vapor-liquid exchange mechanism appears to be the most plausible one. If the heat transfer is the only concern, the contribution of bubbling can be conveniently considered as an increase of the effective thermal diffusivity of liquid near the wall, without looking into the detailed mechanism. If the pumping velocity of the bubble could be estimated, the vapor-liquid exchange model would lead to a simpler method by which the heat transfer could be calculated, as can be seen in an ensuing paper.

Range $\mathrm{BD}$ in Fig. 1 is termed nucleate boiling because of the importance of the nuclei in the boiling process. Higher velocity and subcooling reduce the size and the average lifetime of the bubble and therefore enhance the bubbling frequency and the heat transfer rate to the liquid. On the other hand, higher subcooling and velocity lessen the number of active nuclei for a given superheat. Consequently, the net effect of subcooling and velocity on heat transfer must be weighed simultaneously from these two opposing aspects. 
Surface conditions, such as roughness, wetting character, contamination, and crystal structure, are known to affect considerably the heat transfer in nucleate boiling. Unfortunately, the coexistence of different roughness, different wetting, etc., at different fluid-surface combinations prevents a distinctive separation of the variables which affect the heat transfer and hence a clear definition of these vague terms. At any rate, it can be stated that surface conditions control (a) the effective solid-liquid contact area, (b) the mean size of the originating bubbles, (c) the frequency of bubble generation from each site, (d) the number of active bubble sites, and (e) the superheat of incipient boiling. All these factors can be considered to affect nucleation. Thus, if the heat transfer problem is approached from the nucleation viewpoint, it should be possible to consolidate all these effects into one, or at most two, parameters, which are to be determined by experiments for each kind of fluid-surface combinations.

\section{NUCLEATION}

Volmer(11) was the first to apply the Maxwell-Boltzmann distribution law to the condensation of supersaturated vapor and to suggest that the rate of nucleation be expressed by the following equation:

$$
\mathrm{N}=\mathrm{N}_{0} \mathrm{e}^{-(\Delta \Phi) / \kappa \mathrm{T}}
$$

where $N_{0}$ is the frequency factor, $\kappa$ the gas constant per molecule, and $\Delta \Phi$ the maximum activation energy or the work required to form a bubble of the critical size:

$$
\Delta \Phi=\frac{4}{3} \pi \sigma *^{* 2}
$$

Volmer's theory has been subsequently improved by Eyring (12) and many others. According to Eyring, the frequency factor $N_{0}$ is proportional to the absolute temperature:

$$
\mathrm{N}_{0}=\mathrm{N}_{\mathrm{A}} \kappa \mathrm{T} / \mathrm{H}
$$

where $\mathrm{N}_{\mathrm{A}}$ is the Avogadro number and $\mathrm{H}$ is Planck's constant. Eyring has also modified the maximum activation energy by the addition of the free energy of the molecule moving toward or away from the interface.

Although the kinetic theory has proved quite satisfactory to explain nucleation qualitatively, quantitative calculation shows that boiling cannot be started unless it is facilitated with very large superheat which, however, is not what has been found in experiments. In order to overcome this difficulty, many investigators $(13,14)$ have considered the role of solid surfaces in the modification of the activation energy in Eq. (5). However, such refinements 
have not rendered Eq. (5) usable on a practical level. Therefore, in the study of heat transfer, semiempirical correlation remains an essential tool, for the present and possibly for the future.

Bankoff $(14)$ has recently examined the mechanism of bubble nucleation and the role of contact angle and cavity geometry of the roughened surface. Griffith and Wallis (15) studied the nucleation from a single cavity and found that the gross nucleation properties for a given surface can be characterized by the critical bubble size. Harrison and Levine(16) have studied the effect of wetting by boiling stearic acid from different crystal planes of single crystals of copper and concluded that the contact angles are not suitable criteria for establishing degree of wetting with respect to heat transfer studies.

In 1951 Jens and Lottes (17) correlated a great number of test data for the boiling of high-pressure water into a single equation which shows that the first critical heat flux is proportional to an exponential function of pressure. Gaertner and Westwater(18) recently boiled an aqueous solu. tion of nickel salts and found that the heat transfer rate is proportional approximately to the square root of the number of active bubble sites, which can be expressed by an equation similar to the Maxwell-Boltzmann's distribution law.

\section{FUNDAMENTAL EQUATIONS AND PARAMETERS}

Consider an element of liquid near the wall on the coordinate system sketched in Fig. 2, where the $\mathrm{xz}$-plane is drawn parallel to the wall. If the physical properties of liquids except density in the gravita. tional term are assumed to be constant, the equations of motion and energy can be written as

$$
\begin{aligned}
& \frac{d \vec{V}(\vec{R}, t)}{d t}=\nabla \cdot[\nu \nabla \vec{V}(\vec{R}, t)]-\vec{F} \\
& \frac{d \theta(\vec{R}, t)}{d t}=\nabla[\alpha \nabla \theta(\vec{R}, t)],
\end{aligned}
$$

where the pressure term is omitted, since it will be a function of other quantities, and $\mathrm{d} / \mathrm{d}$ t denotes the differentiation following the motion. If the concept of an eddy thermal diffusivity is introduced, Eq. (9) can be written as

$$
\frac{\partial \theta}{\partial t}+U \frac{\partial \theta}{\partial x}=\nabla[(\alpha+\epsilon) \nabla \theta]
$$




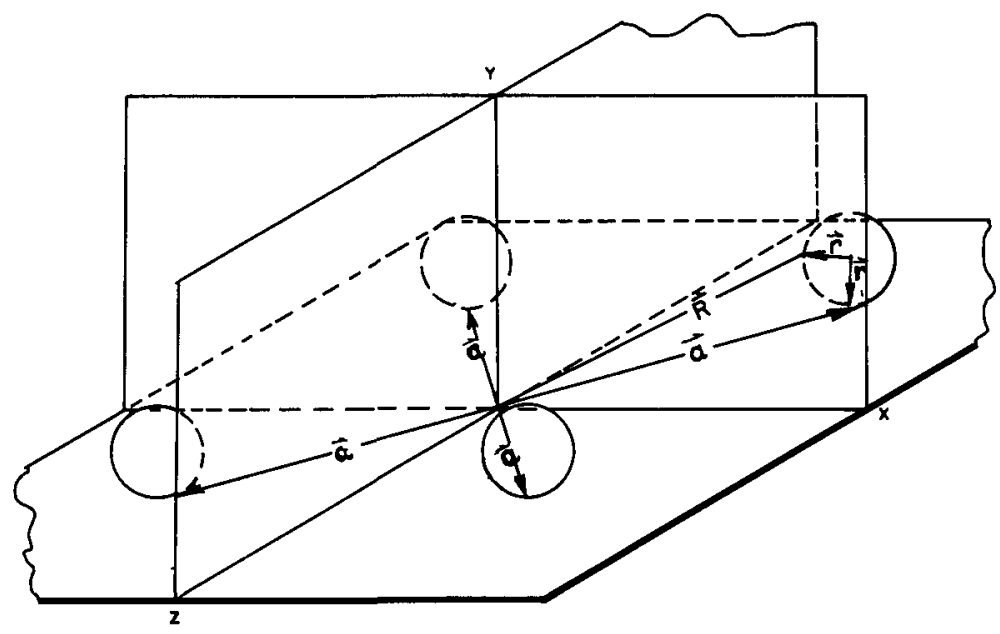

Fig. 2. Coordinate System

The essential boundary conditions are those at the wall and at the moving interface between the bubble and the liquid. The boundary condition for the temperature at the bubble liquid interface can be obtained by assuming that the temperature inside the bubble is constant. Then, when the interface moves a distance $\delta \overrightarrow{\mathrm{r}}$, a quantity of heat $\rho_{\mathrm{v}} \lambda \delta \overrightarrow{\mathrm{r}}$ per unit area of the interface is required in the formation of vapor. This quantity must be equal to the heat transferred from the liquid at the interface.

$$
-\mathrm{k}\left(1+\frac{\epsilon}{\alpha}\right) \frac{\partial \theta}{\partial \overrightarrow{\mathrm{r}}}=\rho_{\mathrm{v}} \lambda \dot{\overrightarrow{\mathrm{r}}} \quad, \quad \theta=0
$$

for

$$
\begin{aligned}
& \vec{r}=\vec{R}-\vec{a}-j \vec{r} \quad, \quad \tau_{1}+n \tau_{2} \geq t \geq n \tau_{2} \\
& n=1,2,3, \ldots .
\end{aligned}
$$

and

$$
\vec{r}=\vec{r} * \text { at } \quad t=0 \text {. }
$$

Since it is of interest only to find additional parameters, the condition at the vapor-liquid interface can be found from equations derived from motions in a potential field. Plesset and $Z_{w i c k}(19)$ and Forster and Zuber $(20)$ have shown that in a superheated liquid the bubble growth rate, including the effect of heat diffusion across the bubble wall, exhibits the following behavior:

$$
\rho\left(\overrightarrow{\mathrm{r}} \cdot \ddot{\vec{r}}+\frac{3}{2} \dot{\vec{r}} \cdot \dot{\vec{r}}\right)=\Delta p-\frac{\dot{2} \sigma}{r},
$$

and for larger values of time

$$
\mathrm{r} \sim \frac{\rho \mathrm{c}_{\mathrm{p}}{ }^{\theta} \mathrm{s}}{\rho_{\mathrm{v}} \lambda}(\alpha t)^{\frac{1}{2}}
$$


Equations (8) to (14) can be written in dimensionless form by selecting $L, U$, and $\theta_{S}$ as the characteristic length, velocity, and temperature, respectively. From these dimensionless equations and by noting that eddy heat transfer is independent of $x$ and $z$, the following parameters are obtained for the determination of $\epsilon / \alpha$ near the wall:

$$
\frac{\rho \mathrm{U}^{2} \mathrm{~L}}{\sigma}, \frac{\Delta \mathrm{p}}{\rho \mathrm{U}^{2}}, \frac{\mathrm{UL}}{\nu}, \frac{\mathrm{g} \beta \theta \mathrm{L}^{3}}{\nu^{2}}, \frac{\nu}{\alpha}, \frac{\partial\left(\theta / \theta_{\mathrm{s}}\right)}{\partial(\mathrm{y} / \mathrm{L})}, \frac{\mathrm{a}}{\mathrm{L}}, \frac{\tau_{1} \mathrm{U}}{\mathrm{L}}, \frac{\tau_{2} \mathrm{U}}{\mathrm{L}}, \frac{\rho \mathrm{c}_{\mathrm{p}} \mathrm{p}_{\mathrm{s}}}{\rho_{\mathrm{v}} \lambda}, \frac{\mathrm{tU}}{\mathrm{L}}, \frac{\mathrm{r}^{*}}{\mathrm{~L}} .
$$

If the liquid is subcooled, Eq. (14) would not be valid, but the parameters derived therefrom still hold, except that an additional parameter, namely, $\theta_{\ell} / \theta_{s}$, must be taken into account.

The dimensionless temperature gradient in (15) represents the Nusselt number and can be written as

$$
\left[\frac{\partial\left(\theta / \theta_{s}\right)}{\partial(y / L)}\right]_{y \rightarrow 0}=\frac{q L}{k \theta_{s}}
$$

The time required for a bubble to grow from its critical to final size depends on the ratio of the final to the critical diameter, $D / 2 r *$. The period of bubble generation from each site and the bubble spacing (or number of bubble sites) are related to the rate of nucleation through the following parameters, which are obtained from Eqs. (5), (6), and (7):

$$
\frac{\mathrm{N}_{\mathrm{A}^{\kappa \mathrm{T}_{\mathrm{S}}}}}{\mathrm{Hr}^{*} / \mathrm{U}} \text { and }\left(\frac{\sigma}{\Delta \mathrm{p}}\right)^{2} \frac{\sigma}{\kappa \mathrm{T}_{\mathrm{s}}}
$$

For steady state, i.e., considerations being made for sufficient length of time, the time parameter $t U / L$ drops from (15). Thus there are twelve parameters remaining to be considered in the determination of the eddy thermal diffusivity and hence the heat transfer, namely,

$$
\frac{\rho \mathrm{U}^{2} \mathrm{~L}}{\sigma}, \frac{\Delta \mathrm{p}}{\rho \mathrm{U}^{2}}, \frac{\mathrm{UL}}{\nu}, \frac{\mathrm{g} \beta \theta_{\mathrm{s}} \mathrm{L}^{3}}{\nu^{2}}, \frac{\nu}{\alpha}, \frac{\rho \mathrm{c}_{\mathrm{p}} \theta_{\mathrm{s}}}{\rho_{\mathrm{v}} \lambda}, \frac{\mathrm{N}_{\mathrm{A}} \kappa \mathrm{T}}{\mathrm{Hr} \mathrm{r}^{*} / \mathrm{U}},\left(\frac{\sigma}{\Delta \mathrm{p}}\right)^{2} \frac{\sigma}{\kappa \mathrm{T}}, \frac{\mathrm{D}}{\mathrm{L}}, \frac{\theta_{\ell}}{\theta_{\mathrm{s}}}, \frac{\mathrm{q} \mathrm{L}}{\mathrm{k} \theta_{\mathrm{s}}}, \frac{\mathrm{r}^{*}}{\mathrm{~L}} .
$$

The first five parameters are the well-known Weber, Euler, Reynolds, Grashof, and Prandtl numbers, the sixth represents the effect of bubble growth, and the seventh and eighth the effect of the nucleation, while the others are self-explanatory. 


\section{BASIC ASSUMPTIONS}

The twelve parameters given in (16) can be further reduced when the following experimental results are observed:

1. In vigorous boiling, the size and orientation of the heating surface have little effect on the heat transfer rate from a unit area of the heater. (21)

2. Boiling curves for the earlier stage of vigorous boiling appear essentially the same for saturated and subcooled boiling with or without forced convection, provided that the heat flux is plotted against superheat, (22) as shown schematically in Fig. 1.

3. The final size of bubble at the wall varies appreciably with subcooling and velocity of flow.

From these experimental results, it can be concluded that the rate of heat transfer at the earlier part of vigorous boiling is practically independent of the final bubble size, dimension of the heater, convective motion, and subcooling. This conclusion holds also for the entire range of vigorous boiling from rough surfaces. However, for boiling from smooth surfaces near the first critical condition, the effect of these factors cannot be neglected. (34)

In view of the fact that the liquid is inten sively agitated by bubbles and that the liquid-vapor interface is not rigid, it can be further assumed that the molecular diffusion is insignificant in comparison with the eddy diffusion once the boiling has become vigorous.

\section{GENERAL EQUATION FOR HEAT TRANSFER DURING VIGOROUS BOILING}

Consider the general case of subcooled forced convection boiling. According to the conclusions reached in the preceding section, the quantities $\nu, k, D, L, U$ and $\theta_{0}$ must vanish in the final correlation of the parameters indicated in (16). The two and only two possible correlations which satisfy these conditions are as follows:

$$
\begin{aligned}
& \frac{\mathrm{qH} \sqrt{\sigma}}{\rho c_{p} \theta_{\mathrm{S}} \mathrm{N}_{\mathrm{A}}\left(\kappa \mathrm{T}_{\mathrm{S}}\right)^{3 / 2}}=\phi(\mathrm{X}, \mathrm{Y}) \\
& \frac{q H \Delta p}{\rho c_{p}{ }^{\theta} N_{A} N_{A} \sigma T_{s}}=\psi(X, Y)
\end{aligned}
$$

where $\phi$ and $\psi$ are functions of the parameters as indicated inside the brackets. Since, however, the lefthand side of Eq. (17) is equal to the 
lefthand side of Eq. (18) multiplied by the parameter $\left[(\sigma / \Delta p)^{2} \sigma / \kappa_{s}\right]^{1 / 2}$, and since the functions and are yet to be determined, Eqs. (17) and (18) are, the refore, identical, so that

$$
j=\left[\left(\frac{\sigma}{\Delta \mathrm{p}}\right)^{2} \frac{\sigma}{k \mathrm{~T}_{\mathrm{s}}}\right]^{1 / \hat{2}} \text {. }
$$

Thus, Eq. (17) is the unique correlation of heat transfer in vigorous boiling and consists of only three parameters: the Stanton number, and two parameters of bubble growth and nucleation.

The heat transfer in pool boiling with or without subcooling can be obtained from Eq. (16) by the same reasoning used in obtaining Eq. (17). The equation so obtained will be identical with Eq. (17). Thus the problem of heat transfer in vigorous boiling is reduced to one of only three parameters. An attempt has been made to derive the function $\phi$ by theory, but it has not been accomplished yet. Since, however, it represents the effect of nucleation in an intensively disturbed field, it should be expressible by the type of equation similar to, but not identical with, Eq. (5), because Eq. (5) is inadequate for practical application, as was pointed out previously. Therefore, the feasible procedure is to modify Eq. (5) by the parameter $Y$ in such a manner that the heat flux density predicted from Eq. (17) should check well with test data for boiling of various liquids from different surfaces under different pressures.

To carry out this aim, the left hand side of $\mathrm{Eq}$. (17) was calculated according to test values of heat transfer rate for a number of organic and inorganic liquids. These results were then plotted against $\mathrm{X}$ with $\mathrm{Y}$ as the parameter It was found that the best representation of those test data by Eq. (17) is obtained by taking the function $\bar{\phi}$ in the following form:

$$
s=C_{1} e^{-n X Y^{-m}}
$$

where $C_{1}$ and $n$ are dimensionless quantities depending on the liquid-surface combinations and $\mathrm{m}$ is equal to 1 and 2.0, respectively, for all the organic and inorganic liquids which have been under investigation. Thus a general equation for the heat transfer in vigorous boiling is obtained by combining Eqs. (17), (19), and (20):

$$
q=c_{1}, c_{p} c_{s} \frac{N_{A}\left(\kappa T_{s}\right)^{3 / 2}}{H \sqrt{5}} e^{-n X Y^{-m}},
$$

where $C_{1}$ and $n$ are to be found from experiments. 
According to the conclusions reached in Section 7, Eq. (21) applies to the following cases:

(a) the entire range of vigorous boiling of saturated liquid in a pool;

(b) the entire range of vigorous boiling from rough surfaces for saturated and subcooled liquids with and without forced convection; and

(c) the earlier part of vigorous boiling from smooth surfaces for saturated and subcooled liquids with forced convection.

Since Avogadro's number, Planck's number and Boltzmann's constant for a given system of units are constant numbers, they can be absorbed into the constant in Eqs. (21). When the British units are used, as given in the Nomenclature in this paper, Eq. (21) becomes

$$
q=C \rho c_{p} \theta_{s} \frac{T_{s}^{3 / 2}}{\sqrt{\sigma}} e^{-n X Y^{-m}}
$$

\section{VIGOROUS BOILING OF ORGANIC LIQUIDS}

In recent years a great number of experimental investigations of the boiling of organic liquids from various heating elements have been made. It would be impossible to cite all of them in this paper. Therefore only those immediately available to the author were used for comparison with the predicted results.

To illustrate how the constant $\mathrm{m}$ in Eq. (2l) can be determined, consider the vigorous boiling of benzene. Calculated values of $X$ and $Y$ for various superheats at pressures from one atmosphere to about eighty per cent of critical point are shown in Table $I$ in the Appendix. It is seen that the exponential function in Eq. (15) becomes vanishingly small for all pressures except those near the critical. This difficulty can be removed by the use of a factor $5 \times 10^{-6} \mathrm{Y}^{-1}$ multiplying the activation energy. The validity of this multiplication factor has been tested for fifteen different organic liquids under various pressures and within the range of superheats in nucleate boiling. Thus the general equation of heat transfer in vigorous boiling of organic liquid is obtained from Eq. (22) by taking $\mathrm{m}=1$ :

$$
q=\operatorname{Coc}_{p} \theta_{s} \frac{T^{3 / 2}}{\sqrt{\sigma}} e^{-n X Y^{-1}}
$$

Test results of Cichelli and Bonilla (24) for boiling of benzene and ethanol from a chromium plated surface are reproduced in Figs. 3 and 4. Mesler and Banchero(25) tested the boiling of benzene, ethanol, acetone, etc., from a well-polished stainless steel tube, and their results are reproduced in Figs. 5, 6, and 7 . 


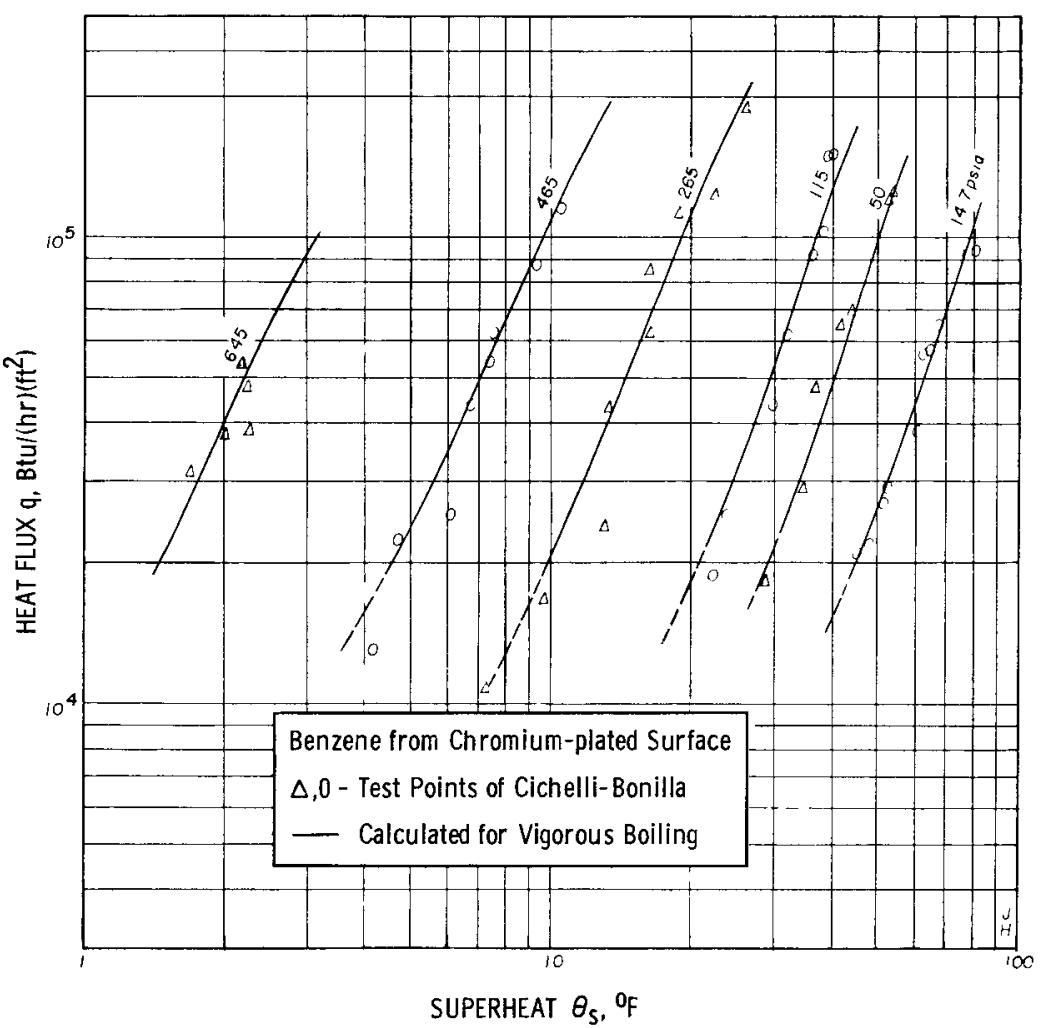

Fig. 3.

Heat Flux versus

Superheat for

Boiling of Benzene

from Horizontal

Chromium-plated

Surface

Fig. 4.

Heat Flux versus

Superheat for Boiling of Ethanol from Horizontal Chromium-plated Surface

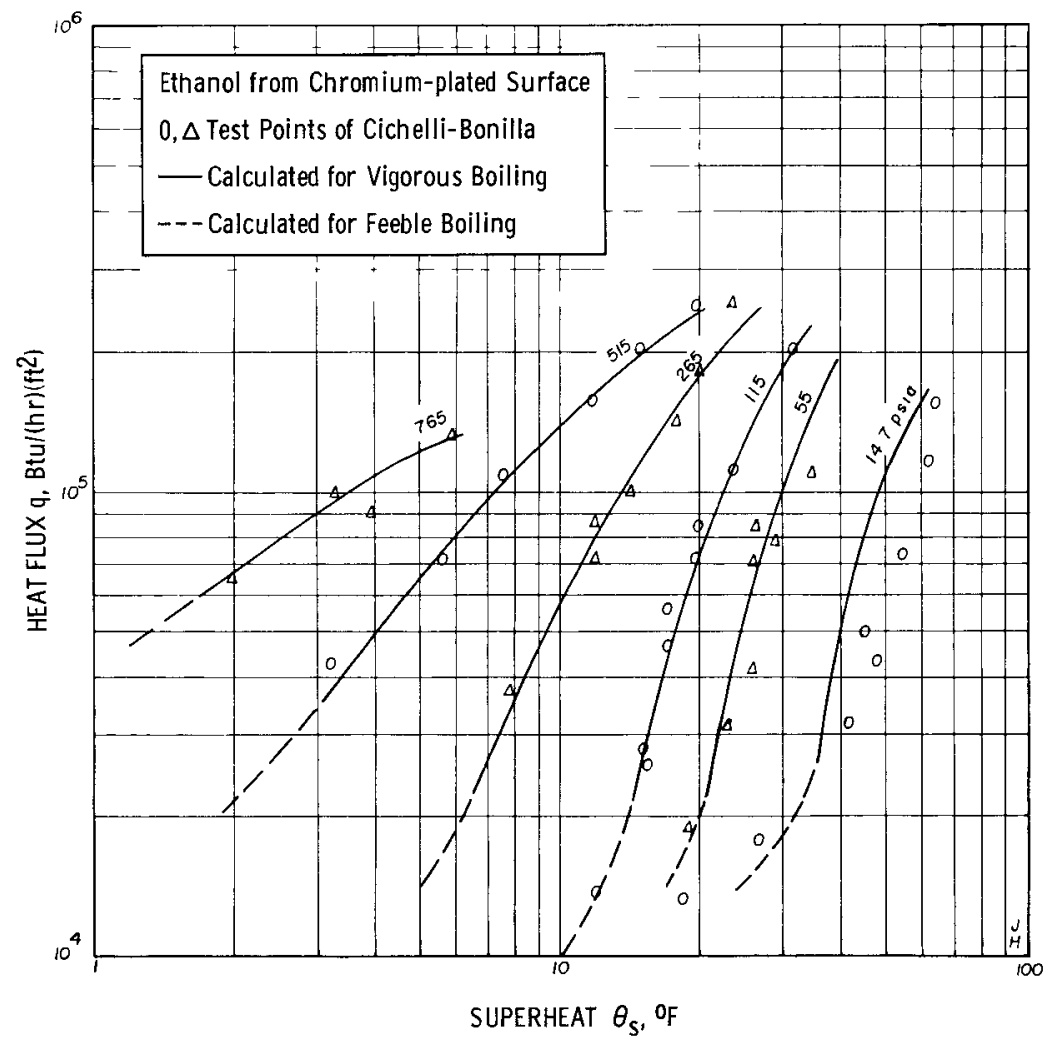




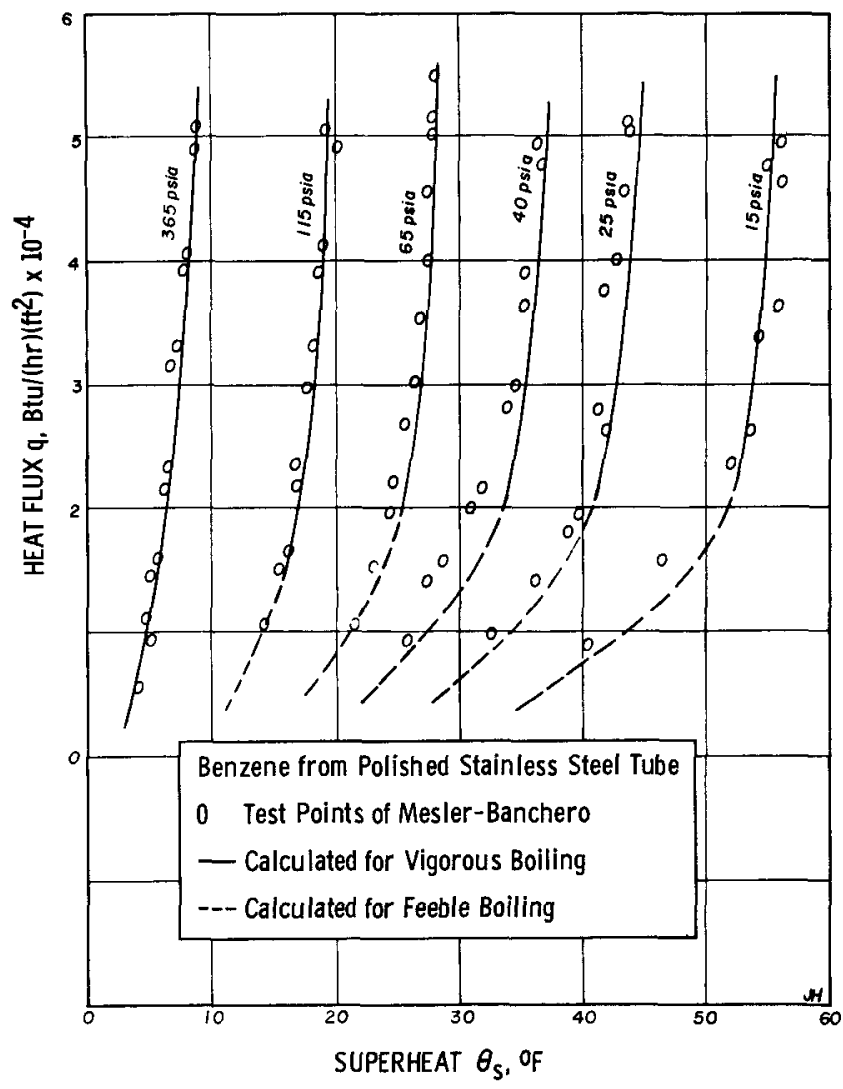

Fig. 5.

Heat Flux versus Superheat for Boiling of Benzene from Well-polished Stainless Steel Tube.

Fig. 6.

Heat Flux versus Superheat for Boiling of Ethanol from Well-polished Stainless Steel Tube.

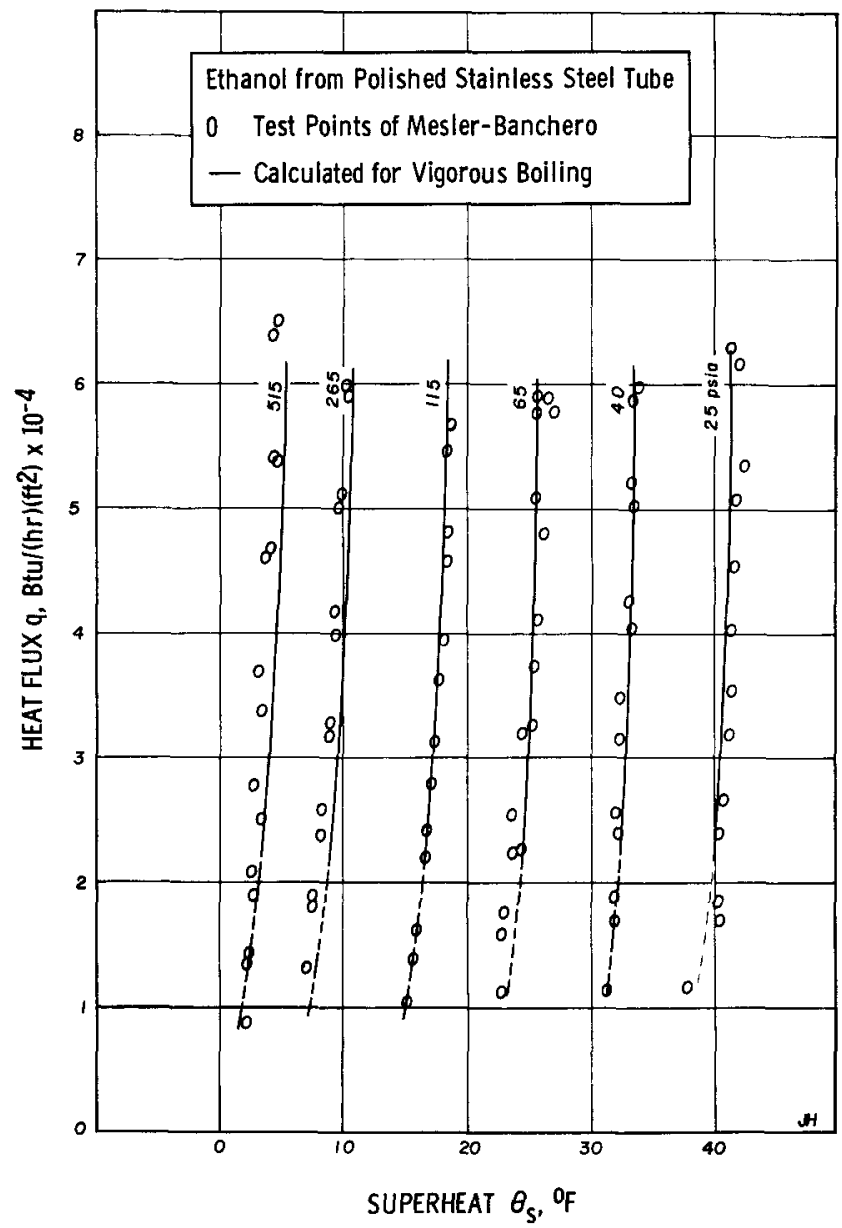




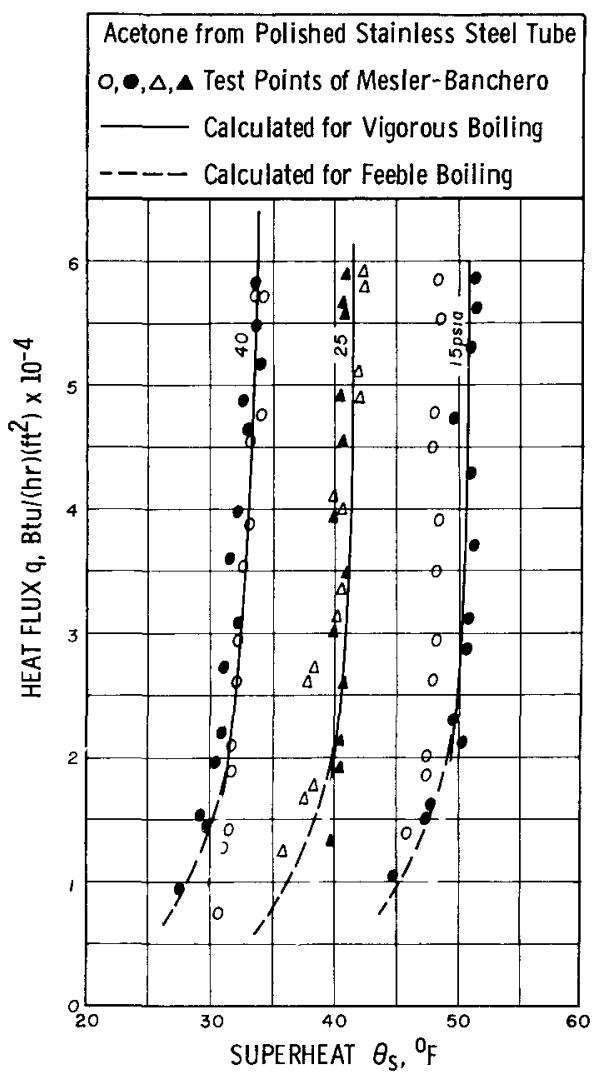

Fig. 7 .

Heat Flux versus Superheat for Boiling of Acetone from Well-polished

Stainless Steel Tube

In Fig. 8. are shown the experimental data of Piret and Isbin(26) for the boiling of isopropyl alcohol, carbon tetrachloride, and normal butyl alcohol in a vertical copper tube with natural circulation. Jordan and Leppert(27) have recently boiled a number of polyphenyls from stainless steel tube, and their results are shown in Fig. 9. Testresults of Westwater and his associates (28) for boiling of isopropanol from a horizontal copper tube are reproduced in Fig. 10.

Calculated values from Eq. (23) are plotted in these figures by solid lines. Values of $\mathrm{C}$ and $\mathrm{n}$ are determined by selecting any two test points of each series of tests, as shown in Table I. Due to the difficulty in the evaluation of the physical properties of acetone at high pressures, calculations have been made only for pressures up to 40 psia. Agreement between calculated and test results appears quite satisfactory, except for ethanol at one atmospheric pressure.

Fig. 8.

Heat Flux versus Superheat for Boiling of Benzene from Stainless Steel Tube with Surface Contaminated.

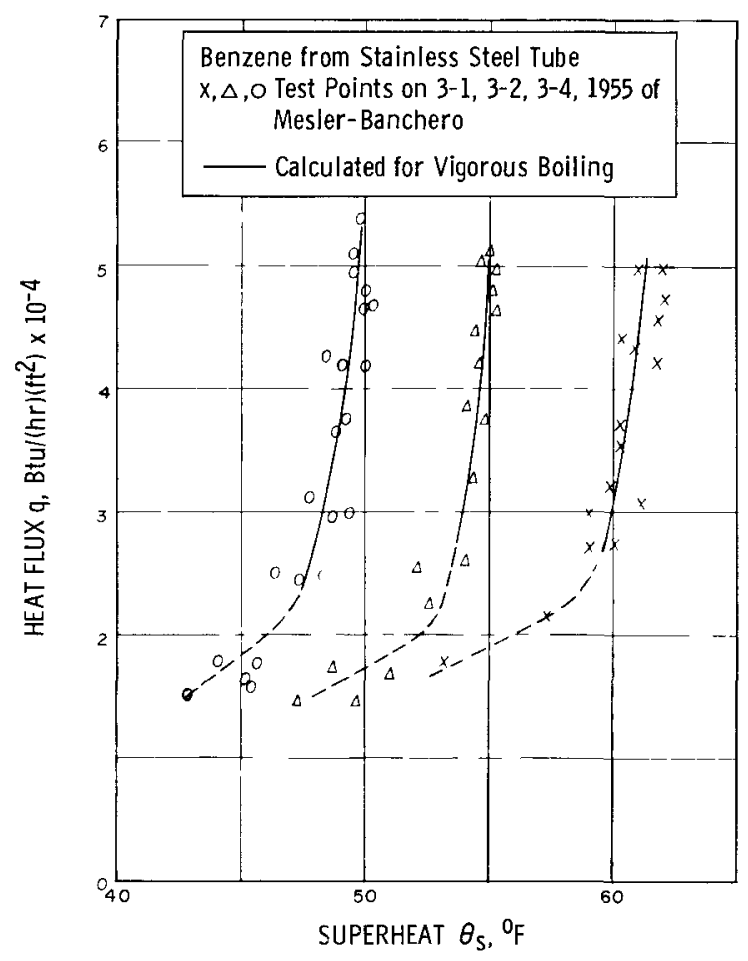




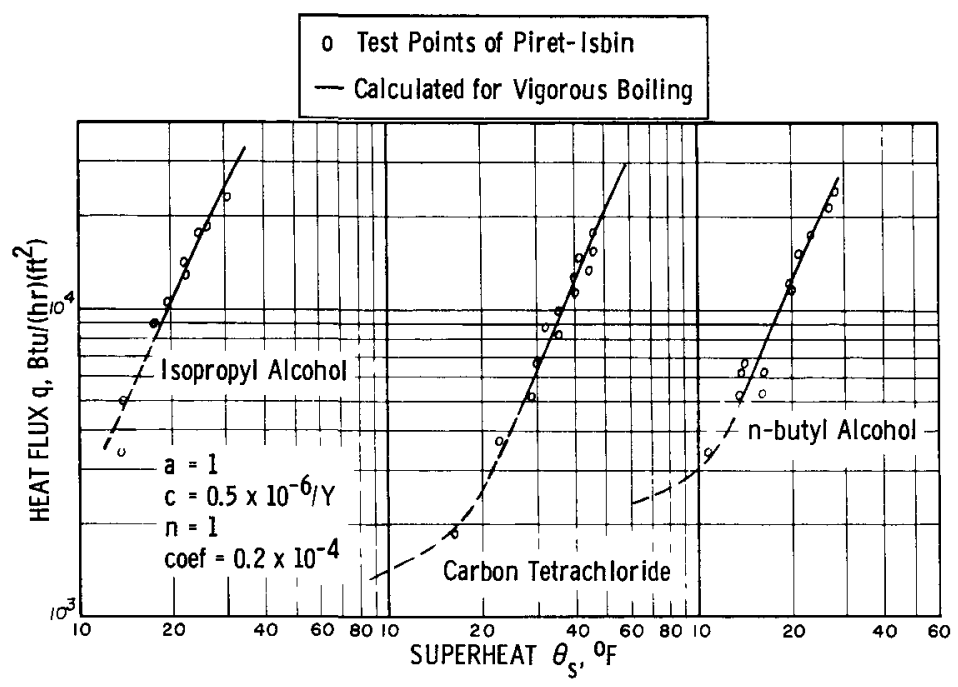

Fig. 9. Heat Flux versus Superheat for Boiling in Vertical Copper Tube

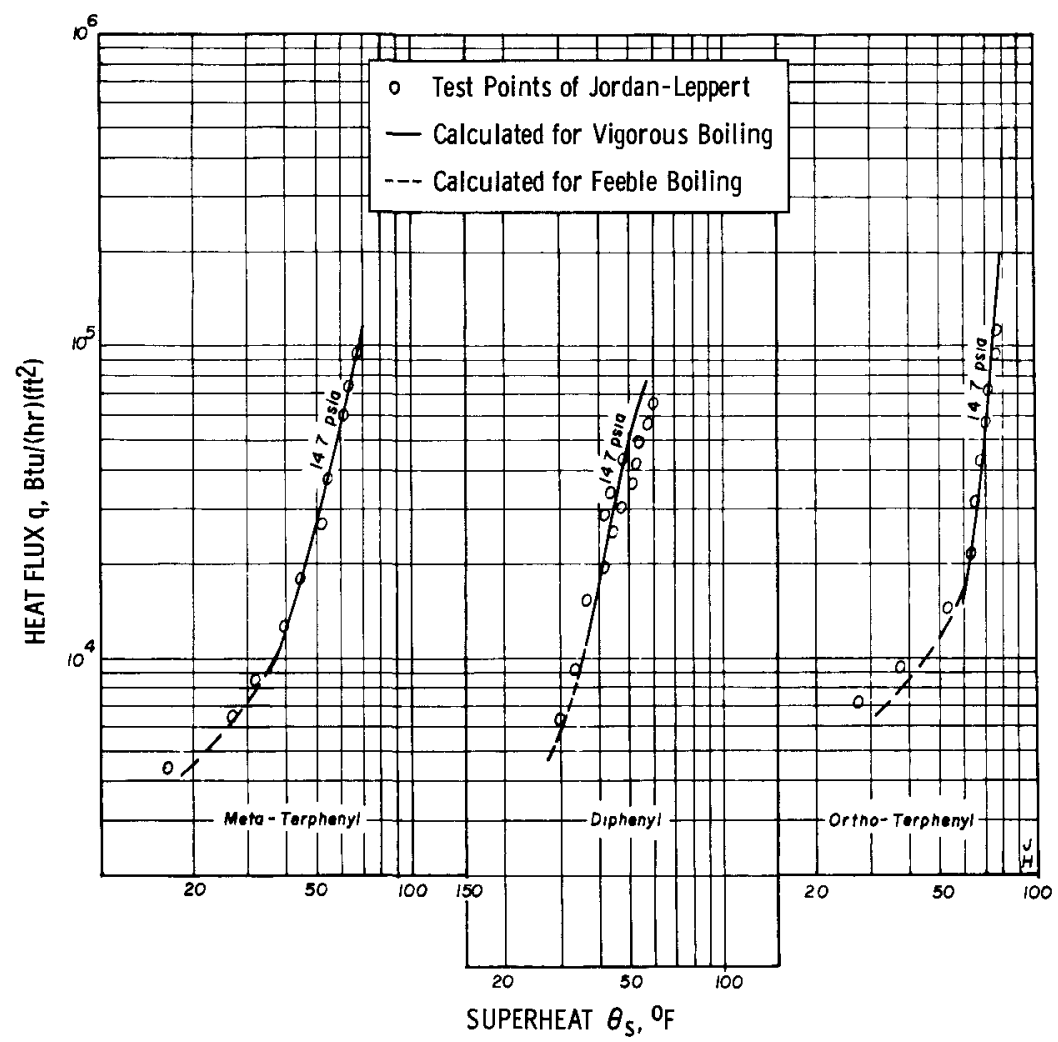

Fig. 10. Heat Flux versus Superheat for Boiling of Polyphenyls

Contamination of the surface reduces the effective superheat due to the temperature drop across the contaminated film. Three sets of test data as recorded by Mesler-Banchero at different date are reproduced in Fig. 11. These data can be accurately predicted by Eq. (23) provided that the effective superheat is used for calculation and the nominal superheat for plotting the curves. Alternatively, proper choice of values of $C$ and $n$ will also yield the correct results without knowing the effective superheat. 
Table I

VALUES OF C AND n IN EQ (23) FOR ORGANIC LIQUIDS AT DIFFERENT SURFACE CONDITIONS

\begin{tabular}{|c|c|c|c|}
\hline Liquid-Surface Combination & Investigators & $\mathrm{C} \times 10^{4}$ & $\mathrm{n}$ \\
\hline $\begin{array}{l}\text { Benzene on chromium-plated } \\
\text { plate }\end{array}$ & Cichelli-Bonilla & 158 & $5 \times 10^{-6}$ \\
\hline $\begin{array}{l}\text { Ethanol on chromium-plated } \\
\text { plate }\end{array}$ & Cichelli-Bonilla & 1.86 & $5 \times 10^{-6}$ \\
\hline Benzene in stainless steel tube & Meslex-Banchero & 4.14 & $2 \times 5 \times 10^{-6}$ \\
\hline Ethanol in stainless steel tube & Mesler-Banchero & 635 & $3 \times 5 \times 10^{-6}$ \\
\hline Acetone in stainless steel tube & Mesler-Banchero & 7.00 & $3 \times 5 \times 10^{-6}$ \\
\hline $\begin{array}{l}\text { Isopropanol in vertical copper } \\
\text { tube }\end{array}$ & Piret-Isbin & 055 & $5 \times 10^{-7}$ \\
\hline $\begin{array}{l}\text { Carbon tetrachloride in vertical } \\
\text { copper tube }\end{array}$ & Piret-Isbin & 041 & $5 \times 10^{-7}$ \\
\hline $\begin{array}{l}\text { n-Butyl alcohol in vertical } \\
\text { copper tube }\end{array}$ & Piret-Isbin & 0.56 & $5 \times 10^{-7}$ \\
\hline Diphenyl in stainless steel tube & Jordan-Leppert & 104 & $2 \times 10^{-6}$ \\
\hline $\begin{array}{l}\text { Ortho-terphenyl in stainless } \\
\text { steel tube }\end{array}$ & Jordan-Leppert & 104 & $2 \times 10^{-6}$ \\
\hline $\begin{array}{l}\text { Meta-terphenyl in stainless } \\
\text { steel tube }\end{array}$ & Jordan-Leppert & 104 & $2 \times 10^{-6}$ \\
\hline Isopropanol in copper tube & Dunskus-Westwater & 1.71 & $3 \times 5 \times 10^{-7}$ \\
\hline
\end{tabular}

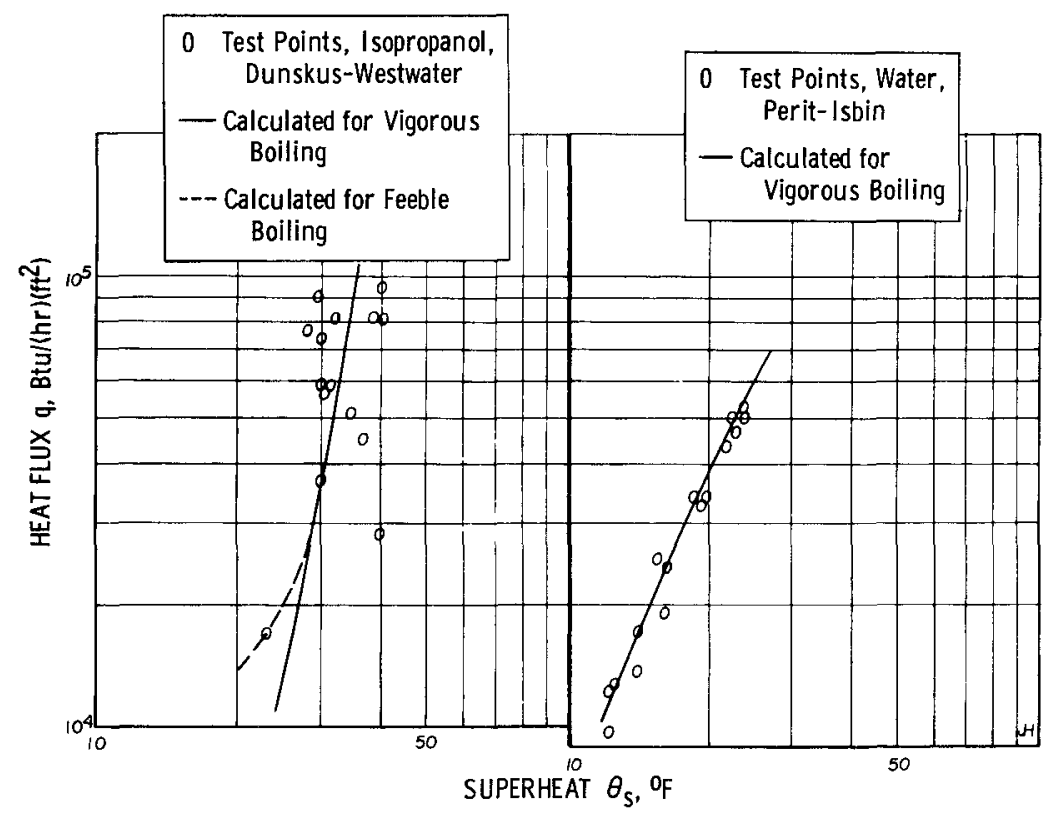

Fig. 11. Heat Flux versus Superheat for Boiling of Isopropanol from Horizontal Copper Tube and of Water in Vertical Copper Tube 


\section{VIGOROUS BOILING OF WATER AND OF MERCURY}

Cichelli and Bonilla (24) boiled water from a slightly dirty chromiumplated surface under pressures from 14.7 to 1000 pounds per square inch. Addoms (29) used a platinum wire and boiled water under pressures up to 2000 pounds per square inch. Tests at one atmospheric pressure have been made by Jakob, (30) Gunther, (7) Lyon et al.,(31) and many others.

To compare the predicted results from Eq. (22) with experimental values of the above mentioned investigators, the modification factor $Y$ is, first of all, to be determined. Calculated values of $X$ and $Y$ are shown in Table II in the appendix. It is seen that to render the Maxwell-Boltzmann distribution law useful for practical application, $n$ must be of the order of $5 \times 10^{-7}$ and $m$ must be larger than unity. After a series of calculations for other inorganic liquids, it is found that the proper value of $\mathrm{m}$ is 2.0 . Thus for the boiling of inorganic liquids, Eq. (22) becomes

$$
\mathrm{q}=\mathrm{C}_{\rho \mathrm{c}_{\mathrm{p}}} \theta_{\mathrm{s}} \frac{\mathrm{T}^{3 / 2}}{\sqrt{\sigma}} \mathrm{e}^{-\mathrm{nXY} \mathrm{Y}^{-2}}
$$

The above mentioned test results can be expressed with fair accuracy by Eq. (24) with values of $\mathrm{n}$ and $\mathrm{C}$ as shown in Table II. Comparison between predicted and test results are shown in Figs. 12, 13, 14 and 15.

$$
\text { Table II }
$$

VALUES OF C AND n IN EQ. (24) FOR WATER BOILING FROM VARIOUS HEATING SURFACES

\begin{tabular}{|l|l|c|c|}
\hline \multicolumn{1}{|c|}{ Surface } & \multicolumn{1}{|c|}{ Investigators } & $\mathrm{C} \times 10^{4}$ & $\mathrm{n} \times 10^{6}$ \\
\hline Slightly dirty, chromium- & & & \\
plated plate & Cichelli-Bonilla & 4.2 & $\frac{1}{2}$ \\
Platinum wire & Addoms & 4.85 & 1 \\
Stainless steel plate & Jakob & 4.1 & $\frac{1}{2}$ \\
& Gunther & 4.1 & $\frac{1}{2}$ \\
Stainless steel annulus & McAdams & 3.42 & $\frac{1}{2}$ \\
Copper tube & Piret-Isbin & 3.21 & $\frac{1}{2}$ \\
Stainless steel tube & Lyon et al. & 13.00 & 2 \\
\hline
\end{tabular}

Test data for boiling of liquid metals shows considerable scatter. Katz(32) stressed the importance of wettability. Lyon et al.,(31) considered that scatter in data comes not only from the probable errors in measurement, but also from the unsteady-state nature of the boiling phenomena. Tests of Lyon et al., for boiling of mercury containing $0.02 \%$ magnesium and $0.0001 \%$ titanium are reproduced in Fig. 15, and can be expressed fairly well by Eq. (24) with values of $n$ and $C$ as follows: 


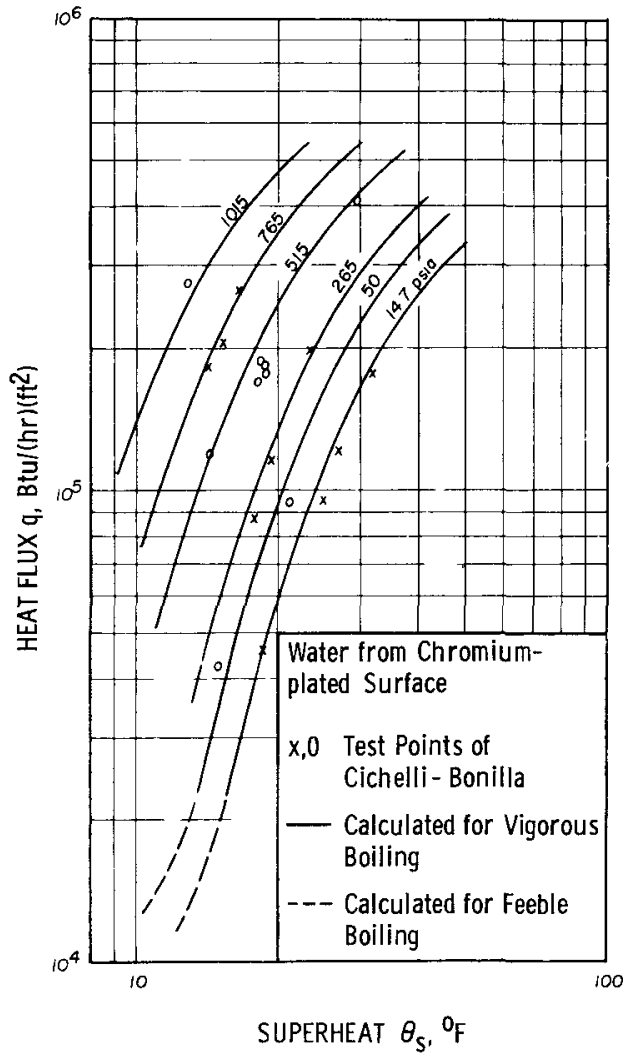

Fig. 12.

Heat Flux versus Superheat for Boiling of Water from Slightly Dirty Chromiumplated Surface

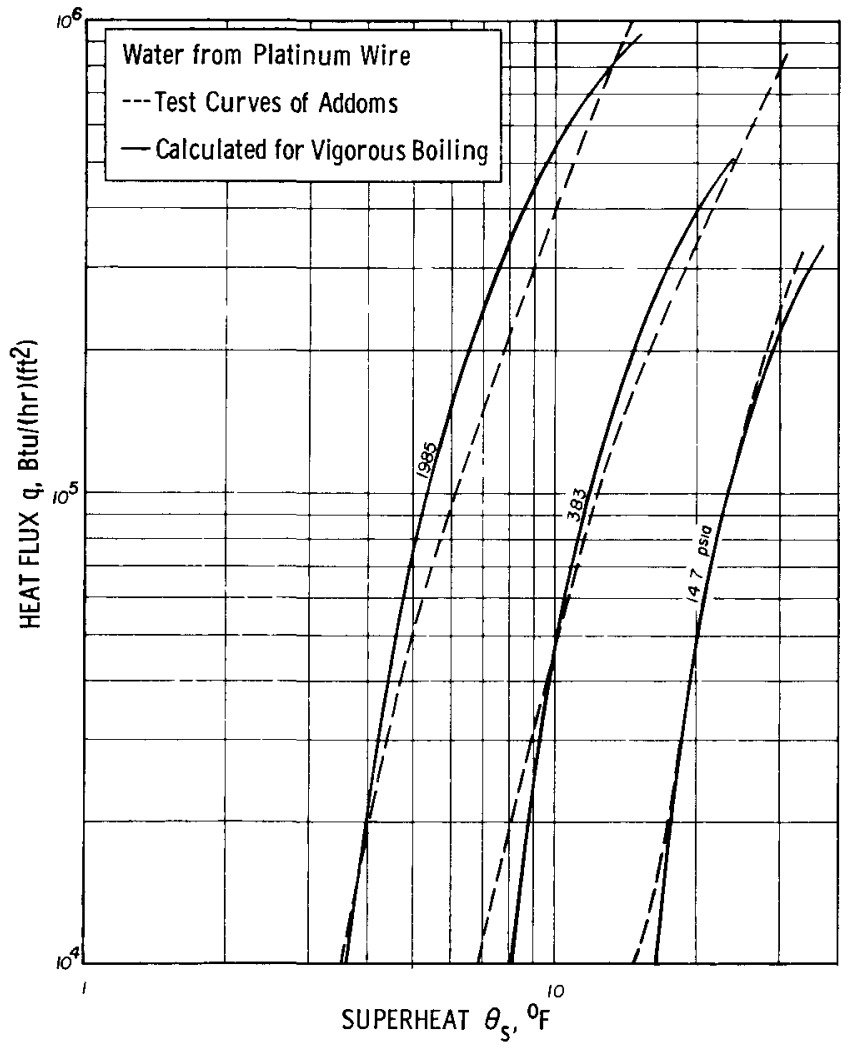

Fig. 13. Heat Flux versus Superheat for Boiling of Water from Platinum Wire 


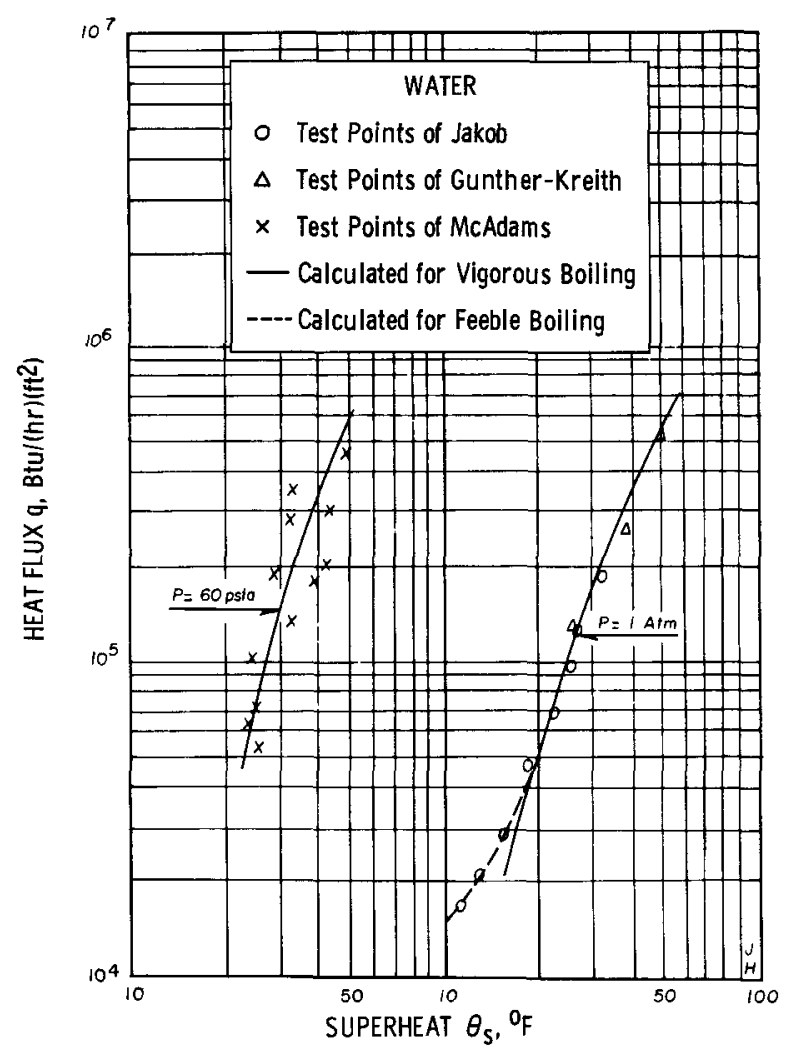

Fig. 14.

Heat Flux versus Superheat for Boiling of Water from Horizontal Surface and Inside Annulus

Fig. 15.

Heat Flux versus Overall Temperature Difference for Boiling of Water from Stainless Steel Annulus

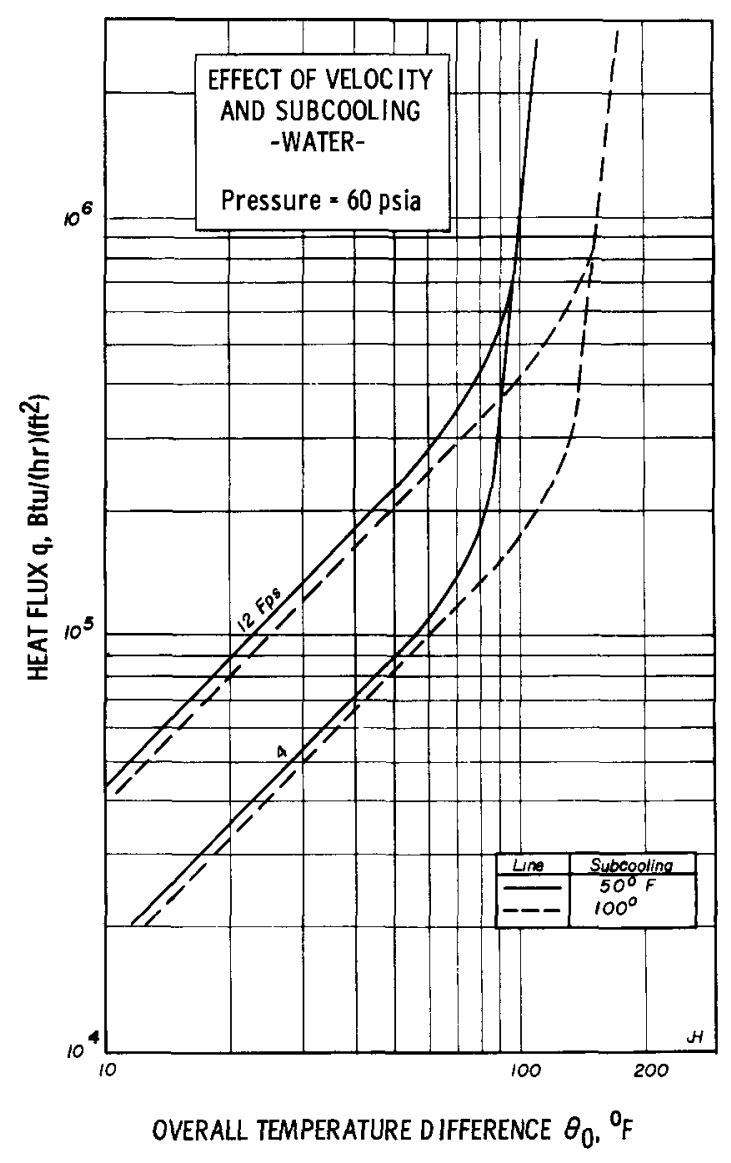



$\mathrm{n}$
C
Added wetting agents
$2 \times 10^{-11}$
$4.15 \times 10^{-3}$
$0.02 \% \mathrm{Mg} \cdot 0.0001 \% \mathrm{Ti}$

Due to the difficulty in evaluating the physical properties of sodium and sodium-potassium alloy, comparison has not been made between calculated and test results. The order of magnitude, however, can be easily estimated from Eq. (24). Calculations have shown that the magnitude of the exponential function in Eq. (21) does not vary too much for systems as different as organic liquids and mercury. The decisive factor in controlling the magnitude of heat flux is the modulus in the rightside of Eq. (21), i.e., $\rho c \theta_{S}\left(T^{3} / \sigma\right)^{l / 2}$. For a given superheat, such as $\theta_{S}=7^{\circ} \mathrm{F}$, this quantity for sodium is many times that for mercury, and hence the heat transfer by boiling sodium should be several times larger than that by mercury.

\section{HEAT TRANSFER DURING FEEBLE BOILING}

At low superheat the bubble population is so low that the process of heat transfer may be considered as that of simple convection. A great number of formulae can be found in the literature about the heat transfer in convection. The simplest ones, yet accurate enough, for free and forced convection of ordinary fluids from a plane wall are probably of the type indicated by Eqs. (25) and (26), respectively:

$$
\begin{aligned}
& q=0.145 \frac{k}{L} \theta_{0}\left(\operatorname{Gr}_{L} \operatorname{Pr}\right)^{1 / 2} \\
& q=0.034 \frac{k}{L} \theta_{0}\left(\operatorname{Re}_{L}\right)^{\mathfrak{C}_{0} 8} \operatorname{Pr}^{2 / 3}
\end{aligned}
$$

For liquid metals which have very high thermal conductivity and very low viscosity, Grosh and Cess (33) assumed potential flow and arrived at the following equation for forced convection over a flat plate:

$$
q=1.00 \frac{\mathrm{k}}{\mathrm{L}} \theta_{0}\left(\operatorname{Re}_{\mathrm{L}} \operatorname{Pr}\right)^{1 / 2}
$$

In the range of feeble boiling, BC of Fig. 1, the transfer of heat by eddy motion may be assumed to be of the same order of 1 mportance as by molecular motion Thus the heat transfer rate can be readily written as:

$$
\begin{aligned}
& \mathrm{q}=0.145 \frac{\mathrm{k}}{\mathrm{L}}\left(1+\frac{\epsilon}{\mathrm{C}}\right)^{2 / 3} \theta_{0}\left(\mathrm{Gr}_{\mathrm{L}} \mathrm{Pr}\right)^{1 / 3} \\
& \mathrm{q}=0.034 \frac{\mathrm{k}}{\mathrm{L}}\left(1+\frac{\epsilon}{\alpha}\right)^{2 / 3} \theta_{0} \operatorname{Re}_{\mathrm{L}}^{0.8} \mathrm{Pr}^{\mathrm{s} / 3} \\
& q=1.00 \frac{k}{L}\left(1+\frac{\epsilon}{i}\right)^{2 / 2} \theta_{0}\left(\operatorname{Re}_{L} \operatorname{Pr}\right)^{1 / 2}
\end{aligned}
$$


for feeble boiling without and with forced convection of ordinary liquids and of liquid metals, respectively.

At vigorous boiling, $\epsilon / \alpha \gg 1$, so that the term unity in Eqs. (28), (29) and (30) can be neglected and these equations reduce to Eq. (21). Accordingly, the eddy thermal diffusivity can be determined for each case:

$$
\begin{aligned}
& \left(\frac{\epsilon}{\alpha}\right)^{2 / 3}=\text { const. } \frac{L \rho c_{p} \theta_{s} N_{A}\left(\kappa T_{S}\right)^{3 / 2} \phi(X, Y)}{k \theta_{0} H\left(G_{L} P_{L}\right)^{1 / 3} \sqrt{\sigma}} \\
& \left(\frac{\epsilon}{\alpha}\right)^{2 / 3}=\text { const. } \frac{L_{p} c_{p}{ }_{s} N_{A}\left(\kappa T_{s}\right)^{3 / 2} \phi(X, Y)}{k \theta_{0} \operatorname{Re}_{L}^{0.8} \operatorname{Pr}^{1 / 3} H \sqrt{\sigma}}
\end{aligned}
$$

for pool and forced convection boiling, respectively, and

$$
\left(\frac{\epsilon}{\alpha}\right)^{1 / 2}=\text { const. } \frac{L_{\rho c_{p}{ }_{s} N_{A}}(\kappa T)^{3 / 2} \phi(X, Y)}{k \theta_{0} P e^{1 / 2} \sigma^{1 / 2}}
$$

for forced convection boiling of liquid metals.

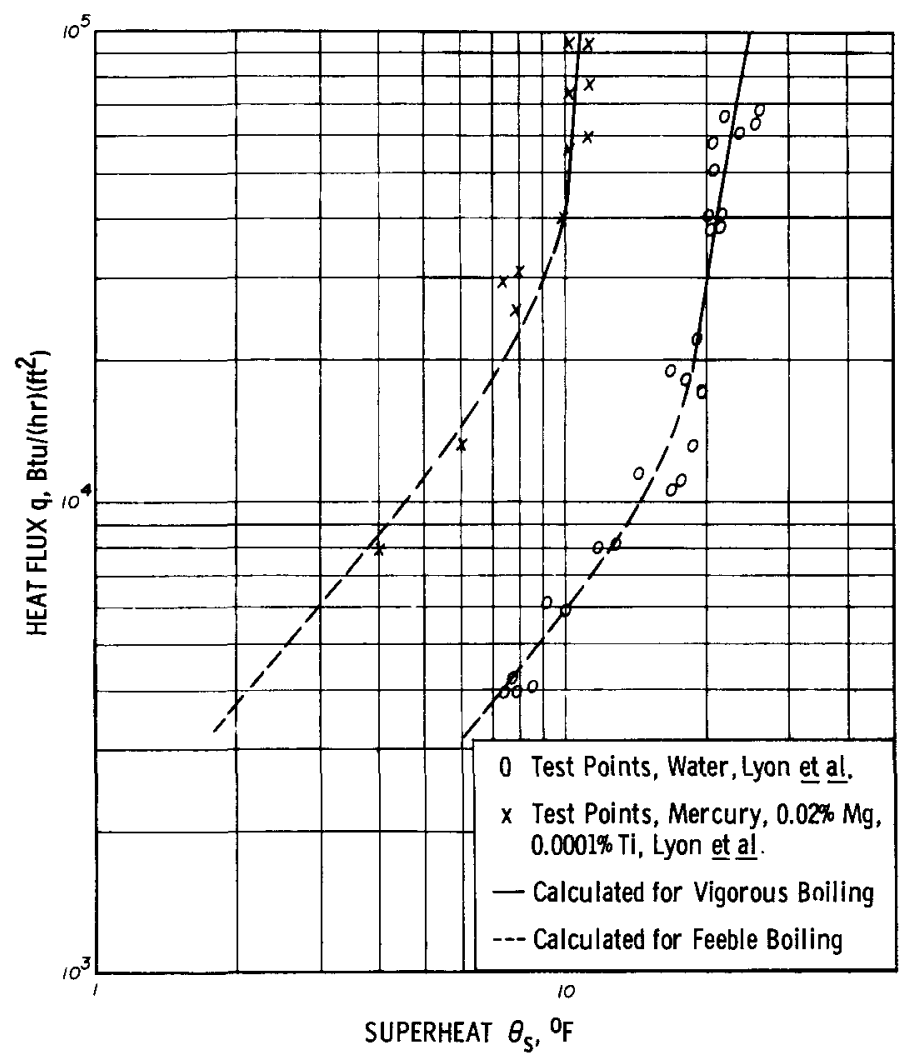

Fig. 16. Heat Flux versus Superheat for Boiling of Mercuryfrom Stainless Tube
Calculated values of heat transfer from Eq. (28) checks well with test data of Jakob(29) for saturated pool boiling of water from a stainless steel plate, as shown in Fig. 15. Calculation from Eq. (29) has also been made for subcooled forced convection boiling of water in an annulus as used in the experiments of McAdams, (21) which is reproduced in Fig. 16. Note that the curves are displaced along the abscissa for each subcooling by values of the temperature difference corresponding to the difference in subcooling. This phenomenon is consistent with McAdams' conclusion.

Curves of feeble boiling for other liquids from different surfaces can be similarly calculated as shown by the dotted lines in Figs. 3 to 15. 


\section{PHYSICAL INTERPRETATION OF EQ. (21)}

Equation (21) was obtained by dimensional analysis of the equations of conservation and the necessary boundary conditions, and by the concept of an eddy thermal diffusivity, which was introduced without looking into the detailed mechanism of boiling heat transfer. To see how the heat is being transferred, it is convenient to write Eq. (21) in the following form:

$$
q=C\left[\rho c_{p} \theta_{s}\right]\left[\frac{{ }_{A}(\kappa T)^{3 / 2}}{H \sigma^{1 / 2}} e^{-n X Y}-m\right] .
$$

Quantities inside the first bracket on the right side of this equation can be considered as proportional to the heat exchange between saturated and superheated liquid near the heater as propelled by the growing bubbles, while those inside the second bracket as proportional to the velocity of this exchange. This confirms, at least in some respect, the "vapor-liquid exchange" mechanism which was recently proposed by Forster and Grief.(3)

Equation (21) can also be written in the form

$$
q=\rho c_{p} \overline{\sigma^{i} v^{y}}=c_{p} \in \frac{\partial \bar{\theta}}{\partial y} \text {, }
$$

where quantities with a bar denote their temporal mean values and the prime indicates the deviation from the mean value Thus $\theta^{\prime}$ is the fluctu ating temperature and $v^{\sharp}$ the fluctuating velocity component in the direction normal to the heating surface. It follows that the boiling heat transfer can be solved according to Prandtl missing length concept, and an analogy between momentum and heat transfer in boiling can be established quantitatively。

\section{MAXIMUM NUCLEATION}

The value of the nucleation function increases at the increase of superheat, but it has a limit as the exponential function approaches to unity. This limit should represent the maximum rate of bubble generation from unit area of the heating surface for a given system. Beyond this limit, further increase of superheat will cause instability of vapor bubbles, and the process of heat transfer changes from nucleate boiling to partial film boiling, as pointed out previously. For example, in the case of boiling of benzene from a chromium plated surface in a pool (see Fig. 3) this condition would occur at the superheat of about $80^{\circ} \mathrm{F}$ under a pressure of one atmosphere and of about $45^{\circ} \mathrm{F}$ at a pressure of $115 \mathrm{psia}$. Instead, in the case of boiling of benzene, from a rough surface (see Fig. 5) this condition would occur at a considerably larger superteat, for the value of $\mathrm{n}$ is larger than that of smooth surface, as can be seen from Table II. In reality, how * ever, the first critical condition occurs, in general, at a superheat much 
less than these values because the maximum rate of bubble generation is limited by the stability of a bubble moving in the liquid. (23)

For saturated boiling of ethanol from a chromium-plated surface in a pool, curves in Fig. 4 become quite flat, particularly at higher pressures, when the superheats have reached to certain values. Calculation of $\mathrm{Eq}$. (21) shows that at these superheats values of the nucleation function $\phi$ have approached the limit. It is a known fact, however, that subcooling and velocity of forcing flow have a considerable influence to the heat transfer as the first critical condition is approached. Thus, near the first critical condition Eq. (21) should not apply to subcooled and forced convection boiling from very smooth surfaces. For rougher surfaces, however, this limitation is removed and the validity of Eq. (21) extends to the critical condition.

\section{CONCLUSIONS AND REMARKS}

The general agreement between predicted and test results for a rather large variety of liquids, pressures, surface conditions and geometry of the heater would support the validity of the formula derived in this paper and the following tentative conclusions:

1. The high heat transfer rate in nucleate boiling is due principally to the pumping action of bubbles at the earlier stage of their growth.

2. The sizes of bubbles at which they leave the surface have practically no effect to the heat transfer at earlier stage of vigorous boiling.

3. Due to the intensive turbulence caused by bubbles, the transport properties dependent upon the molecular character of the liquid, namely, thermal conductivity and viscosity, have little effect to the heat transfer.

4. Liquids that possess larger values of density, specific heat, boiling point, and lower values of surface tension give higher heat trans fer rate. Liquids which have larger variations of vapor pressure with temperature are always desirable for boiling heat transfer.

In spite of the fact that the formulae recommended in this report predict fairly well the test results of previous investigators, they should not be considered as final. Further refinement and improvement will be made, particularly with respect to the following points:

(i) The fact that the constant $m$ in Eq. (21) is equal to one for organic liquids and two for inorganic liquids indicates the lack of universality of the modification factor for the activation energy. 
(ii) The excessive deviation between predicted and test results for the boiling of ethanol at a pressure of one atmosphere requires further refinement of the formula.

(iii) Since a part of the coefficient $C$ in Eq. (21) belongs to the nucleation function $\phi$, which varies with surface conditions as indicated

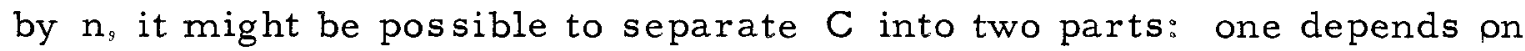
the surface condition, whereas the other should be a universal constant, or, at most, a function of the shape of the heater. For illustrative pur pose, let $n$ be written as the products of two numbers, $n_{1}$ and $n_{2}$, as shown in Tables I and II. Then $\mathrm{C}=\mathrm{C}_{1} \mathrm{e}^{\mathrm{n}_{1}}$ and Eq. (21) becomes

$$
\left.\mathrm{q}=\mathrm{C}_{1} \rho \mathrm{c}_{\mathrm{p}} \theta_{\mathrm{s}} \frac{\mathrm{T}_{\mathrm{S}}^{3 / 2}}{\sqrt{\sigma}} \mathrm{e}^{-\mathrm{n}_{1}\left(\mathrm{n}_{2} \mathrm{XY}\right.} \mathrm{Y}^{-\mathrm{m}}-1\right)
$$

such that $10^{4} C_{1}=0.58,0.69,0.35$, etc, for benzene, ethanol. acetone, etc, and is independent of surface conditions. Yet, these numbers do not appear as a universal constant, though they depend only on liquids. It is hoped, however, that these refinements could be done in the near future.

For saturated pool boiling from smooth surfaces, the calculated curve appears concave downward at the increase of superheat. It is shown in Reference 34 that forced convection and subcooling tend to straighten the curve, but the curve becomes again concave at a higher superheat. In the case of boiling from rough surfaces, however, the in crease of superheat increases the rate of nucleation so fast that the first critical condition can be reached at a comparatively lower superheat and. therefore, the effect of forced convection and subcooling is practically insignificant throughout the entire range of vigorous boiling.

Some students in the area of boiling heat transfer usually believe that by the adjustment of two arbitrary constants in an equation the calculated results could always be brought into agreement with test data. More careful study, however, will obviate this belief. It is not difficult to devise an equation with two adjustable coefficients valid for a given liquid within a limited range of system pressure, but it is not a simple job to get one equation to work well for any liquid-surface combination at any pressure. 


\section{$\underline{\text { References }}$}

1. Nukiyama, S., J. Soc. Mech. Engrs. (Japan) 37, 367 (1934).

2. Rohsenow, W. M., A Method of Correlating Heat Transfer Data for Surface Boiling of Liquids, Trans. ASME, 74, 969 (1952).

3. Forster, H. K. and Grief, R., Heat Transfer to Boiling Liquids Mechanism and Correlations, J. Heat Transfer, ASME (Feb. 1959).

4. Levy, S., Generalized Correlation of Boiling Heat Transfer, ASME Paper No. 58-HT-8 (1958).

5. Chang, Y. P. and Snyder, N. W., Heat Transfer in Saturated Boiling, Chem. Eng. Prog. Symposium Ser., 55, No. 29(1960).

6. Jakob, M., Heat Transfer, John Wiley and Sons (1949), p. 624.

7. Gunther, F.C. and Kreith, F., Photographic Study of Bubble Formation in Heat Transfer to Subcooled Water, Heat Transfer and Fluid Mechanics Institute, Berkeley (1949), p。1 13.

8. Rohsenow, W. M. and Clark, J.A., A Study of the Mechanism of Boiling Heat Transfer, Trans。ASME, 73, 609 (1951).

9. Ellion, M. E., A Study of the Mechanism of Boiling Heat Transfer, Memo.No. 20-88, Jet Prop. Lab., California Inst. of Technology, (March 1954).

10. Edward, D. K., The Role of Interface Mass Transfer, Thesis M.S., University of California, Berkeley (1956).

11. Volmer, M. and Weber, A., Keimbildung in Ubersättigten Gibilden, Z. Phys. Chem. 119, 277 (1925).

12. Eyring, $H_{0}$, Viscosity, Plasticity, and Diffusion as Examples of Absolute Reaction Rate, J. Chem. Phys., 4, 283 (1936).

13. Frenke1, J., Kinetic Theory of Liquids, Oxford Press, (1946), Ch. VII.

14. Bankoff, S.G., The Prediction of Surface Temperatures at Incipient Boiling, Chem. Eng. Prog. Symposium Series 29, 55 (1959).

15. Griffith, P. and Wallis, J. W., The Role of Surface Conditions in Nucleate Boiling, Ch. Eng. Prog. Sym. Series 30, 56 (1960).

16. Harrison, W. B. and Levine, Z., Wetting Effects on Boiling Heat Transfer, ASME Paper No. 57-HT-29 (1957).

17. Jens, W. H. and Lottes, P. A., Analysis of Heat Transfer, Burnout, Pressure Drop and Density Data for High Pressure Water, ANL-4627, (1951).

18. Gaertner, R, F. and Westwater, J.W., Population on Active Sites in Nucleate Boiling Heat Transfer, Ch. Eng. Prog.Sym. Series 30, 56 (1960). 
19. Plesset, M. S. and Zwick, S. A., The Growth of Vapor Bubbles in Superheated Liquids, J.Appl. Phys., 25, 493 (1954).

20. Forster, H. K. and Zuber, N., Growth of a Vapor Bubble in a Superheated Liquid, J. Appl. Phys. 25, 474(1954).

21. Reference 6, p.638.

22. McAdams, W. Ho, Heat Transmission, McGraw-Hill Book Co. (1954) p. 392.

23. Chang, Y. P., The First Critical Condition of Heat Transfer in Boiling of Saturated and Subcooled Liquids with and Without Forced Convection, Argonne National Laboratory (to be published)

24. Cichelli, M. T. and Bonilla, C. F. Heat Transfer to Liquids under Pressure, Trans. AICHE, XLI, 392 (1945).

25. Mesler, R. B. and Banchero, J. T., Effect of Superatmospheric Pressures on Nucleate Boiling of Organic Liquids, J.AICHE, 102 (March 1958).

26. Piret, E. L. and Isbin, H.S., Natural Circulation Evaporation Two-phase Heat Transfer, Chem. Eng. Prog. 50, 305 (1954).

27. Jordan, D. P. and Leppert, G., Nucleate Boiling Characteristics of Organic Reactor Coolants, Nuclear Science and Engineering, 5, 349 (1959).

28. Dunskus, T. and Westwater, J.W., The Effect of Trace Additives on the Heat Transfer to Boiling Isopropanol, University of Illinois.

29. Reference 22, p. 382 .

30. Reference 6, p.639.

31. Lyon, R. E。, Foust, A. S. and Katz, D. L., Boiling Heat Transfer with Liquid Metals, Chem。Eng. Prog. Sym. Series.

32. Katz. D. L. Liquid Metal Handbook, ed. by Jackson, C B., (1955).

33. Grosch, R, J a and Cess, R, D. Heat Transfer to Fluids with Low Prandtl Numbers for Flow across Plates and Cylinders of Various Cross Section, ASME Trans., 80 (1958)。

34. Chang, Y. P., A Phenomenological Theory of Boiling Heat Transfer, Progress Report, AEC Contract No.AT(11-1)-785, University of Notre Dame, Notre Dame, Indiana. 


\section{APPENDIX}

Table I

SAMPLE CALCULATION OF ACTIVATION ENERGY FOR BOILING OF BENZENE

\begin{tabular}{|c|c|c|c|c|}
\hline $\begin{array}{c}\text { Pressure } \\
\text { p, atm }\end{array}$ & $\begin{array}{c}\text { Superheat } \\
\theta_{\mathbf{S}},{ }^{\circ} \mathbf{F}\end{array}$ & $\mathrm{Y}$ & $X$ & $X Y^{-1} \times 10^{-5}$ \\
\hline 14.7 & $\begin{array}{l}40.3 \\
49.6 \\
52.4 \\
55.6 \\
74.8\end{array}$ & $\begin{array}{l}32.55 \\
40.10 \\
42.30 \\
44.95 \\
60.50\end{array}$ & $\begin{array}{l}1.927 \times 10^{7} \\
1.081 \times 10^{7} \\
0.885 \times 10^{7} \\
0.765 \times 10^{7} \\
0.312 \times 10^{7}\end{array}$ & $\begin{array}{l}5.921 \\
2.697 \\
2.094 \\
1.704 \\
0.524\end{array}$ \\
\hline 50 & $\begin{array}{l}24.7 \\
34.5 \\
42.1 \\
44.7 \\
50.5\end{array}$ & $\begin{array}{l}7.25 \\
10.10 \\
12.36 \\
13.10 \\
14.8\end{array}$ & $\begin{array}{l}3.77 \times 10^{6} \\
1.54 \times 10^{6} \\
1.065 \times 10^{6} \\
0.948 \times 10^{6} \\
0.731 \times 10^{6}\end{array}$ & $\begin{array}{l}5.20 \\
1.50 \\
0.685 \\
0.720 \\
0.495\end{array}$ \\
\hline 115 & $\begin{array}{l}15.0 \\
20.0 \\
31.6 \\
37.1\end{array}$ & $\begin{array}{l}2.255 \\
3.01 \\
4.74 \\
5.56\end{array}$ & $\begin{array}{l}9.58 \times 10^{5} \\
5.46 \times 10^{5} \\
1.97 \times 10^{5} \\
1.355 \times 10^{5}\end{array}$ & $\begin{array}{l}4.250 \\
1.189 \\
0.416 \\
0.244\end{array}$ \\
\hline 265 & $\begin{array}{r}7.2 \\
12.5 \\
15.7 \\
18.8 \\
26.2\end{array}$ & $\begin{array}{l}0.538 \\
0.932 \\
1.172 \\
1.40 \\
1.96\end{array}$ & $\begin{array}{l}1.27 \times 10^{5} \\
0.57 \times 10^{5} \\
0.42 \times 10^{5} \\
0.277 \times 10^{5} \\
0.129 \times 10^{5}\end{array}$ & $\begin{array}{l}2.36 \\
0.615 \\
0.356 \\
0.197 \\
0.066\end{array}$ \\
\hline 365 & $\begin{array}{r}5.1 \\
7.2 \\
10.0\end{array}$ & $\begin{array}{l}0.273 \\
0.386 \\
0.536\end{array}$ & $\begin{array}{l}0.874 \times 10^{5} \\
0.437 \times 10^{5} \\
0.176 \times 10^{5}\end{array}$ & $\begin{array}{l}3.172 \\
1.032 \\
0.330\end{array}$ \\
\hline 465 & $\begin{array}{l}4.1 \\
6.1 \\
6.9\end{array}$ & $\begin{array}{l}0.174 \\
0.26 \\
0.294\end{array}$ & $\begin{array}{l}0.278 \times 10^{5} \\
0.132 \times 10^{5} \\
0.107 \times 10^{5}\end{array}$ & $\begin{array}{l}1.6 \\
0.506 \\
0.367\end{array}$ \\
\hline 645 & $\begin{array}{l}1.7 \\
2.2 \\
2.3\end{array}$ & $\begin{array}{l}0.0615 \\
0.0796 \\
0.0837\end{array}$ & $\begin{array}{l}0.295 \times 10^{2} \\
0.260 \times 10^{2} \\
0.249 \times 10^{2}\end{array}$ & $\begin{array}{l}0.0048 \\
0.0033 \\
0.0030\end{array}$ \\
\hline
\end{tabular}


Table II

SAMPLE CALCULATION OF ACTIVATION ENERGY FOR BOILING OF WATER

\begin{tabular}{|c|c|c|c|c|}
\hline $\begin{array}{c}\text { Pressure } \\
\text { p, atm }\end{array}$ & $\begin{array}{c}\text { Super heat } \\
\theta_{\mathbf{S}},{ }^{\circ} \mathrm{F}\end{array}$ & $Y$ & $X$ & $X Y^{-2} \times 10^{-6}$ \\
\hline 14.7 & $\begin{array}{l}18.1 \\
25.2 \\
26.7 \\
31.8 \\
40.0 \\
60.0\end{array}$ & $\begin{array}{r}30.1 \\
42.0 \\
.44 .5 \\
53.1 \\
66.7 \\
100.1\end{array}$ & $\begin{array}{l}1.66 \times 10^{9} \\
8.10 \times 10^{8} \\
7.10 \times 10^{8} \\
4.66 \times 10^{8} \\
2.50 \times 10^{8} \\
0.78 \times 10^{8}\end{array}$ & $\begin{array}{l}1.86 \\
0.46 \\
0.35 \\
0.165 \\
0.056 \\
0.008\end{array}$ \\
\hline 50 & $\begin{array}{l}14.9 \\
22.0\end{array}$ & $\begin{array}{r}8.1 \\
12.0\end{array}$ & $\begin{array}{l}22.4 \times 10^{8} \\
9.38 \times 10^{7}\end{array}$ & $\begin{array}{l}3.40 \\
0.65\end{array}$ \\
\hline 265 & $\begin{array}{l}18.1 \\
23.3\end{array}$ & $\begin{array}{l}2.21 \\
2.83\end{array}$ & $\begin{array}{l}3.54 \times 10^{6} \\
2.02 \times 10^{6}\end{array}$ & $\begin{array}{l}0.73 \\
0.25\end{array}$ \\
\hline 515 & $\begin{array}{l}14.2 \\
18.7 \\
20.0\end{array}$ & $\begin{array}{l}0.99 \\
1.30 \\
1.397\end{array}$ & $\begin{array}{l}1.06 \times 10^{6} \\
4.7 \times 10^{5} \\
4.62 \times 10^{5}\end{array}$ & $\begin{array}{l}1.07 \\
0.39 \\
0.24\end{array}$ \\
\hline 765 & $\begin{array}{l}14.3 \\
16.4\end{array}$ & $\begin{array}{l}0.734 \\
0.842\end{array}$ & $\begin{array}{l}4.64 \times 10^{5} \\
3.17 \times 10^{5}\end{array}$ & $\begin{array}{l}0.80 \\
0.44\end{array}$ \\
\hline 1015 & $\begin{array}{r}5.4 \\
13.0 \\
35.4\end{array}$ & $\begin{array}{l}0.223 \\
0.535 \\
1.460\end{array}$ & $\begin{array}{l}4.67 \times 10^{5} \\
2.06 \times 10^{5} \\
0.741 \times 10^{4}\end{array}$ & $\begin{array}{l}0.93 \\
0.71 \\
0.034\end{array}$ \\
\hline 2000 & $\begin{array}{r}4.2 \\
14.2\end{array}$ & $\begin{array}{l}0.120 \\
0.407\end{array}$ & $\begin{array}{l}0.383 \times 10^{5} \\
0.121 \times 10^{4}\end{array}$ & $\begin{array}{l}2.66 \\
0.76\end{array}$ \\
\hline
\end{tabular}

